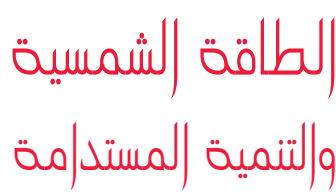

مجلة علمية مُحكُمة نصف سنوية تصدر عن مركز بحوث ودراسات الطاقة الشمسية

\title{
التيارات الهوائية النفاثة كقوة مولدة للطاقة الكهربية في ليبيا
}

\author{
عبد الفتاح الهادي الشيباني \\ المركز الوطني للأرصاد الجويت- طرابلس - ليبيا \\ بريد إلكتروني:Afshibani@gmail.com
}

الملخص: إن مصادر الرياح العليا ضخمت للغايت، ووفقا للتقديرات يمكن لهذه الرياح أن تزود ليبيا بقسط كبير من الطاقت الكهربائيت. من بين الأمثلت الدالت على التكنولوجيات الهندسيت المعاصرة يٌّ هذا المجال هو ابتكار جيل جديد من التوربينات

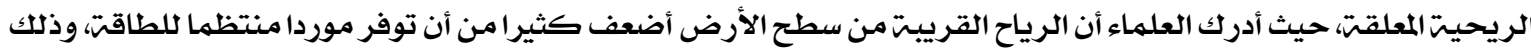

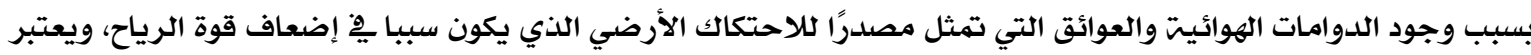

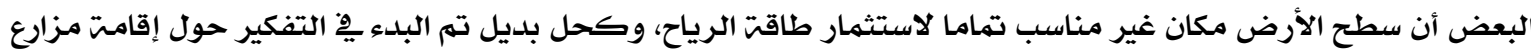

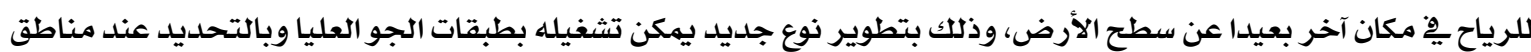

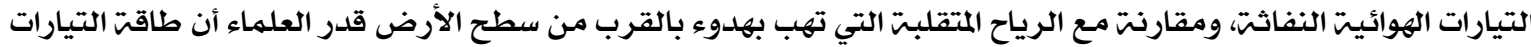
النفاثت تزيد بألف مرة عن تلك التي يمكن تجميعها من أعتى الرياح هِّ أعالي التلال. وحتى نتمكن من تقديم صورة واضحت

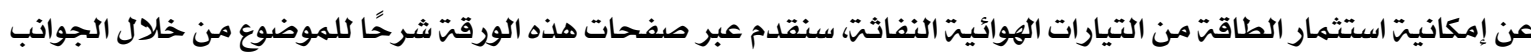
الآتيت: كيف بدأت رحلت التوربينات الريحيت المعلقت، ميزاتها، والصعوبات التي تواجهها، فوائدها وجدواها الاقتصاديت، الدورة

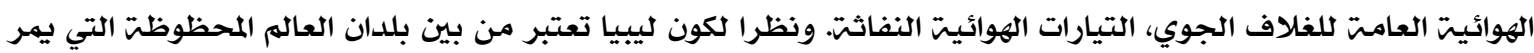

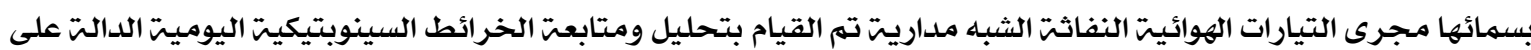
سرعتو واتجاه الرياح النفاثت والارتفاعات التي وجدت عليها لفترة 60 شهرا متتاليا ابتداء من 01 يناير 2003، حتى 31 ديسمبر 2007، إضافت إلى تحليل بيانات الرصد اليومي للرياح النفاثت التي سجلتها محطت الأجواء العليا بطرابلس خلال الفترة من

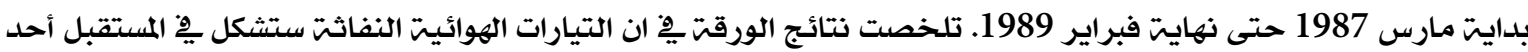

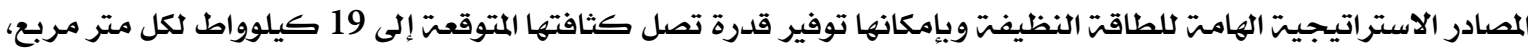

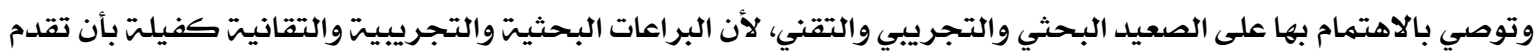

الكثير من الحلول المثيرة لمشكلات الطاقت بِّ ليبيا.

Abstract: The supreme wind sources are extremely huge, and according to estimations, these winds can supply Libya with great quantity of electrical energy. Among the examples of contemporary engineering technologies in this field, is to create a new generation of Airborne Wind Turbines. Scientists realized that winds near the Earth's surface are too weak to provide a regular source of energy due to the presence of aerobic swirls and obstacles, which represent a source of ground friction being the cause of weakening wind power. Some consider that the Earth's surface is a totally inappropriate place for investing wind energy. As an alternative solution, we start to think about the establishment of wind farms in another place away 
from the Earth's surface by developing a new type that can run within the upper-air layers, precisely at jet streams areas. In comparison with fluctuating winds blowing gently near the Earth's surface, scientists estimate that the energy of jet streams increases a thousand times than that can be gathered from the most powerful winds on high hills. To be able to provide a clear picture of the possibility of energy investment of jet streams, we shall present, across the pages of this paper, an explanation of the topic through the following aspects: How do Airborne Wind Turbines' trip start, their advantages and difficulties faced, benefits and economic feasibility, General Atmospheric Circulation and jet streams. Since Libya is among the fortunate countries in the world, through which subtropical jet streams pass, we made an analysis and follow-up of daily synoptic charts, which show jet winds' speed, direction and their altitudes for a period of 60 consecutive months starting from January 1, 2003 until December 31, 2007. Also, an analysis was made of daily observational data of jet winds recorded by Tripoli Upper-air Station during the period from the beginning of March 1987 until the end of February 1989. The paper's results summarized that jet streams will be in the future one of the important clean energy strategic sources, and can provide a capacity, whose expected intensity is up to 19 kilowatts per square meter. It recommends giving attention to jet streams at the research, experimental and technological levels because research, experimental and technological proficiencies can provide more exciting solutions for energy problems in Libya.

كلمات استدلاليتة: طاقت التيارات الهوائيت النفاثت، التربينات الريحيت المعلقتة

نحو منحنيات التكلفت الهندسيت. وعلى هذا الأساس سنحاول عبر صفحات هذه الورقت التركيز على إحدى التكنولوجيات

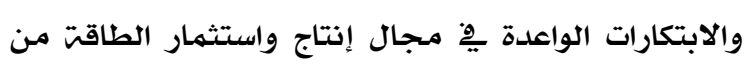
الغلاف الجوي والتي باتت تعرف بالتقنيات الريحيت المعلقت، التي تنبثق من مبدأ السعي للحصول على مصادر جديدة

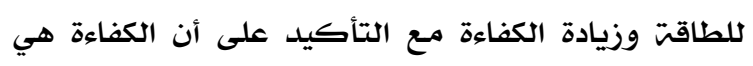

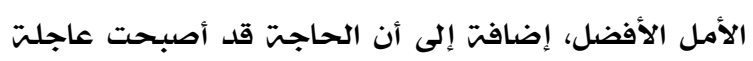

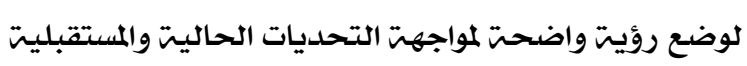

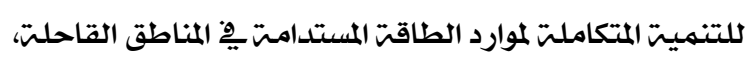
ويمكن تحقيق ذلك بواسطت الدعم الجاد لمؤسسات البحث العلمي والتطوير التقني من أجل تأمين ودعم الخبرات العلميت والتقنيت الفعالت للقيام بدور التطوير والابتكار. لذا

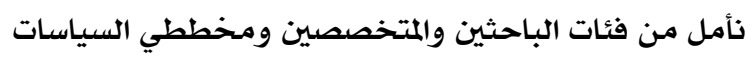
الاقتصاديت والبيئيت بالمؤسسات الوطنيت الذين ولئخصن يهتمون بمجالات الطاقت المتجددة دراستة هذا الموضوع بشكل أشمل من كافت جوانبه وإدراجه ضمن سّلم الأولويات بهدف

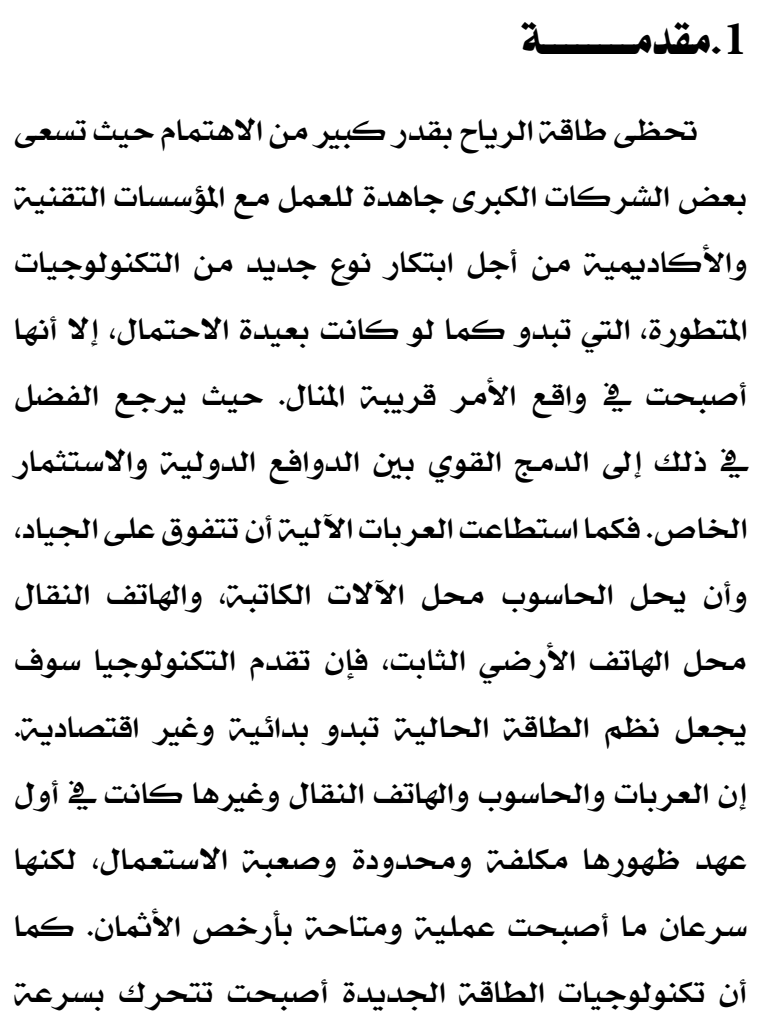


إنتاج مئات الميجاواطات من الطاقت الكهربيت [8، 9]. وقد

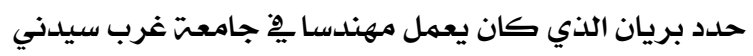
آنذاك، حدد كيفيت إمكانيت استخلاص الطاقت من الغلاف الجوي عبر سلسلت من التوربينات الريحيت التي تصدر أزيزا

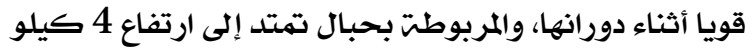

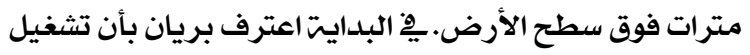

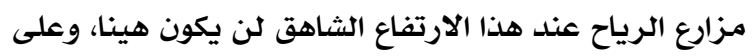
الرغم من ذلك فقد بنى هو وفريقه عددا من التوربينات الريحيت الدوارة التي تعتبر تهجينا بين طائرة الهيليوكبتر والطائرة الورقيت. وبعد ثلاثين عاما من الأبحاث، أصبح

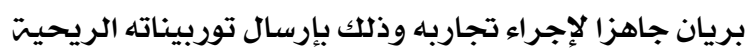

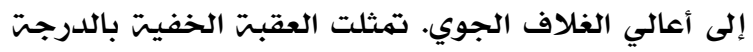

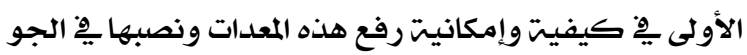

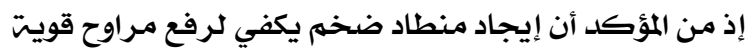
ومولدات للطاقت عدة كيلومترات ِِّ الجو سوف يكون مكلفا دون شك. ويٌ هذا الصدد قال بريان؛ لرفع توربينات تستطيع

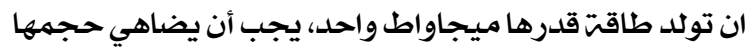
طائرة جامبو نفاثت. بنى بريان توربينته المعلقت الأولى هيج

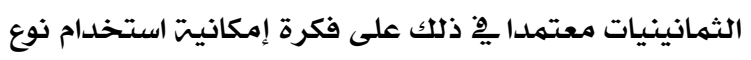
من طائرات الهيليوكبتر التي لا تعمل بالطاقت لكنها تتسلق

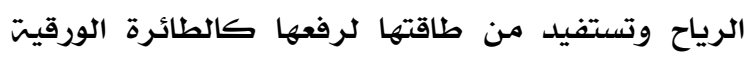
وتدعى (الجيروميل) أي التوربينت الدوارة. وقد قام باختبار

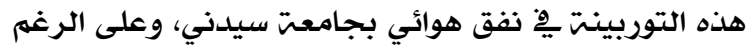

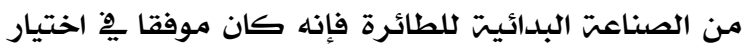

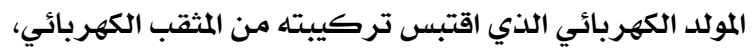
وكان لدى المحركات طاقت قويت قياسا بالوزن وأنتج كل

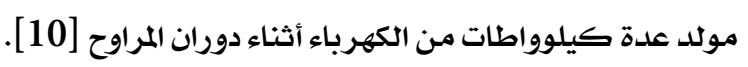

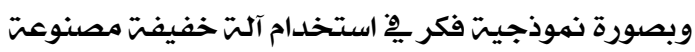
من أنابيب معدنيت قويتّ تتكون من جسم هيكلي وطائرة ذات ذيل صغير وجناحين متشابكين بشكل انسيابي، وعند طريف

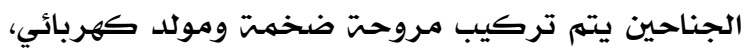
وأثناء دورانها توفر المروحتان طاقت رفع قويت تكفي لإبقاء مروحئ

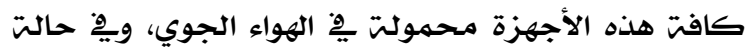

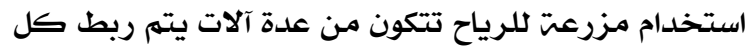

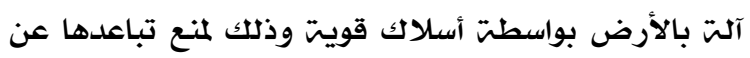

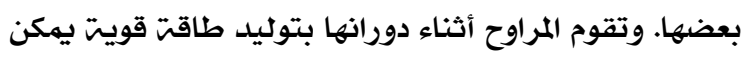
تمريرها عبر أسلاك الومونيوم موصلت للكهرباء إلى محطنت
اكتشاف مدى إمكانيت الاستفادة الليبيت الذاتيت من طاقت التيارات الهوائيت النفاثت الكامنت بطبقات الجو العليا. وحتى التئ

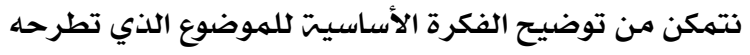

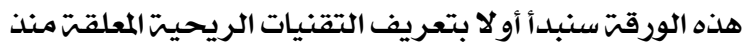
بداياتها ثم نستتبح ذلك بتقديم شرح موجز للدورة الهوائيت

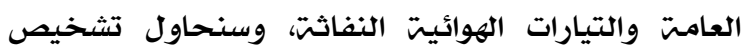

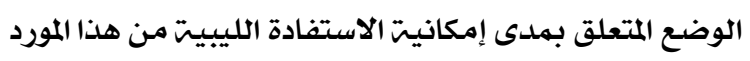

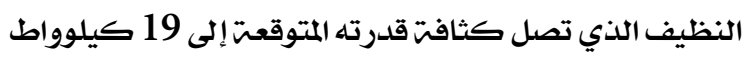
لكل متر مربع، وسنأتي بين ثنايا هذه الجوانب على العديد من المواضيع الهامت بالخصوص.

\section{2. كيف بـدأت رحسلـة التوربينات الريحية المعلقة}

ِِِِ أواخر السبعينيات من القرن الماضي عندما شغلت

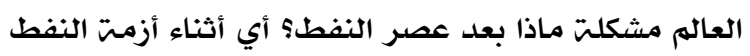

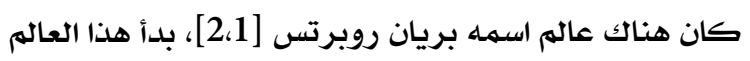
يفكر بطاقت الرياح ولكن ليس من خلال الرياح السطحيت

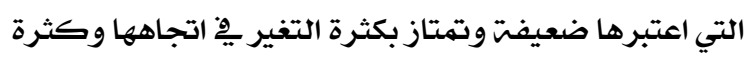

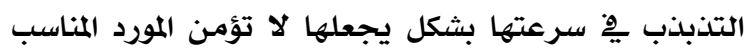

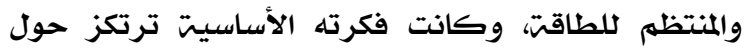
استغلال مصادر طاقت الرياح وذلك من خلال التيارات

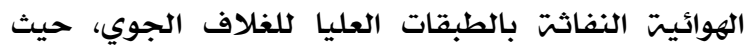
تعتبر التيارات الهوائيت النفاثت بمثابت خزان ضخم للطاقتة،

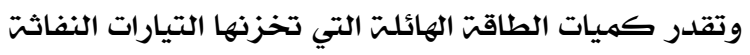

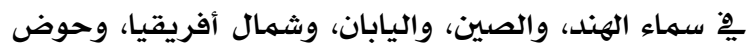

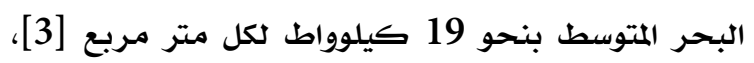

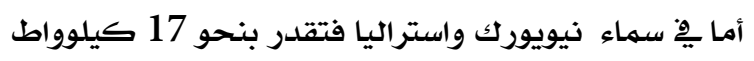
لكل متر مربع، بينما يقدر معدل طاقت الرياح السطحيت

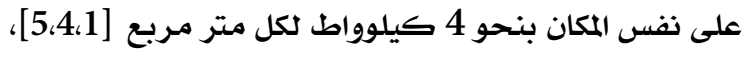
وبعبارة أخرى فإن الطاقت المتوفرة بطبقات الجو العليا تزيد بمائتة مرة عن الطاقت التي يوفرها أي مصدر آخر للطاقت

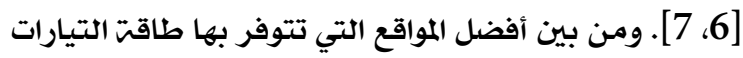

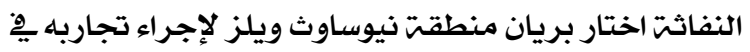

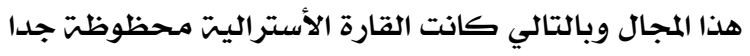

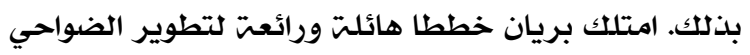

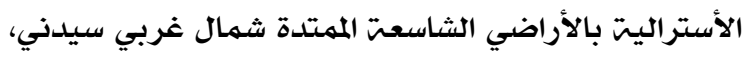

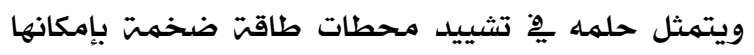


من التحليق إلى ارتفاع 30 مترا، وخلال هذه المرحلت قرر

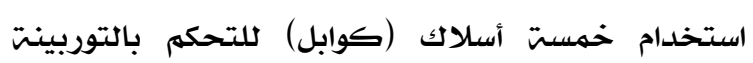
الهوائيت التي بدت وكأنها طائرة ورقيت.

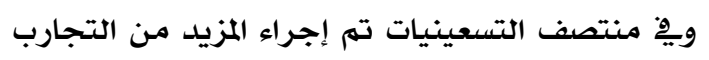
بجامعت غربي سيدني حيث تم تعيين بريان كبروفسور يِ

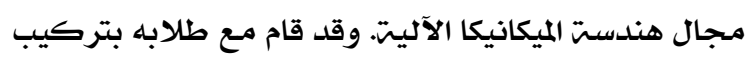
جهاز جبرسكوب على الطائرة لغرض تحديد الارتفاع، إضافت إلى جهاز معالجت ذاتيتة وبرنامـج حاسوب للتحكم آليا

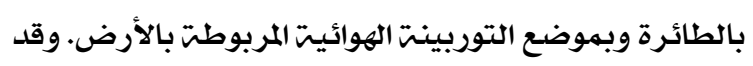
أصبح لدى بريان الآن العديد من المتطلبات الهامت مثل قوة الرفع والطاقت والثبات والتحكم يٍ الطائرة. ومنذ ذلك الحين ركز بريان على جعل تصاميمه تتسهم بالكمال وتحديد نسبت الطاقت المثاليت إلى الوزن. كما قام فريقه بتحليل معطيات

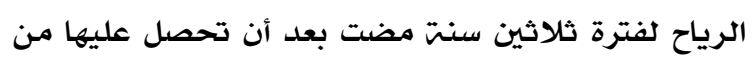
مكتب الأرصاد الجويت، وقد أظهرت هذه المعطيات أن طاقت التيارات الهوائيت النفاثت يِّ شمالي نيوسـاوث ويلز تصل إلى 19 كيلوواط لكل متر مربع على ارتفاع 9 كيلومترات

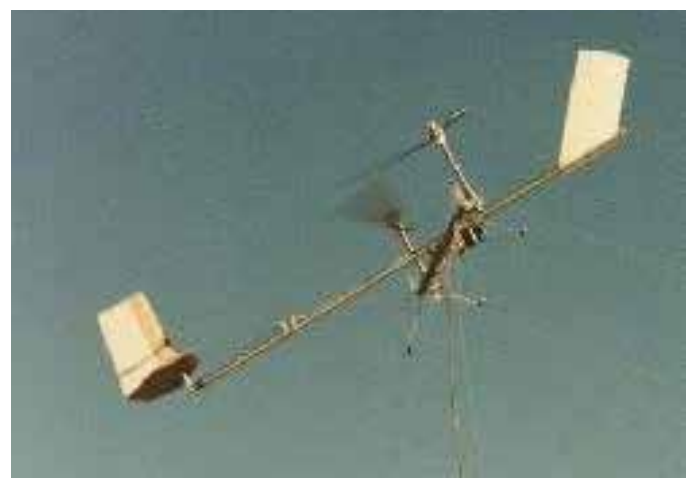

الشكل (1). التجارب الأولى لبريان.

ناحيت الاستثمار يتمثل بتحليق التوربينت عند ارتفاع نحو 4

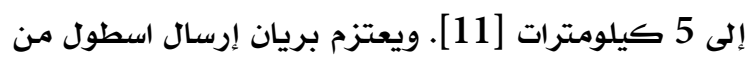

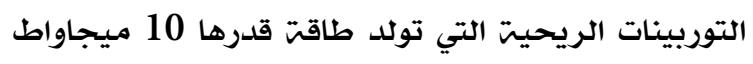
مربوطت فوق حقل دائري يبلغ قطره نحو 28 كيلومترًا لتوفير حيز كاف لإبقاء الأجهزة متباعدة عن بعضها مسافت كيلومتر وهو هامش هبوط آمن ِِِ حالت الطوارىى. ويِ الأسفل توجد أكشاك للصيانت ومحولات لتوصيل المولدات الكهربيت المحمولت جوا بشبكت الكهرباء الأرضيتت.
أرضيت ومن ثم إلى شبكت كهربيت حيث تقدر الطاقت

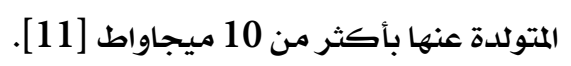

ونظرا لعدم توفر مورد مالي مستمر، اضطر بريان

الانتظار لسنوات أخرى قبل أن تتمكن طائرته الصغيرة من التحليق. وعندما سنحت لله الفرصت وتهيأت له الظروف بدأ بريان بإجراء الخطوة الأولى من تجاربه حيث قام مع فريقه بتحميل توربينته الهوائيت الضخمت على مقطورة مـع زوج من المراوح التي يبلغ طولها أربعت أمتار، وباستخدام سيارته جر تلك المقطورة إلى مطار مهجور، وسار بسيارته المحملت بالمراوح لمحاكاة الرياح القويت فارتفعت الآلت المربوطت نحو متر يِّ الهواء. أثبتت هذه التجربت أن توربينت هوائيت بهذا الحجم بإمكانها توليد طاقت كافيت لتمكينها من التحليق وتوفير الكهرباء. لكن بريان استنتج الكثير من الملاحظات حول افتقار الطائرة للتوازن والثبات ِِّ الهواء الجوي. ونظرا لأن الآلت كانت تتأرجح بصورة غير متوقعت تعين على الباحثين تركيب أذرع معدنيت على مؤخرة السيارة لحمايت أنفسهم، وتمثلت الخطوة التاليت باختبار هذه التوربينت الهوائيت الأوليت يِّ جولبيرن بنيوساوث ويلز حيث تمكنت

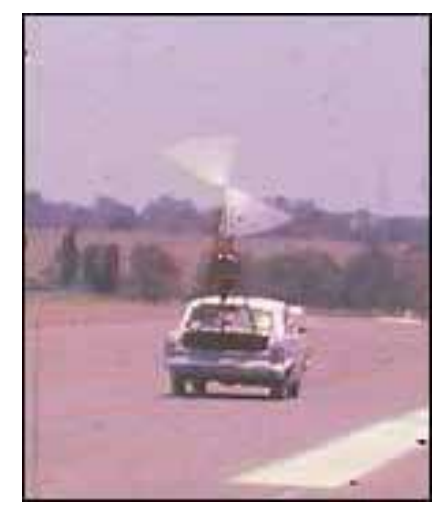

وضع بريان خطت لإقناع شركات الطاقت بجدوى مشروعه، لكنه أدرك أيضا أنه للحصول على أفضل النتائج من توربيناته الهوائيت الدوارة المعلقت يتعين أن لا يتم تعليقها على ارتفاعات شاهقت جدا، حيث تكون طاقت الرياح أقوى ما يهكن يِّ بؤرة التيار النفاث وتتلاثى تدريجيا بالابتعاد عنها. لكن استغلال طاقت الرياح يْ بؤرة التيار الهوائي النفاث تعني استخدام كوابل طويلت بصورة غير عمليت من ناحيت تكلفت التصنيع والصيانت، وبالنظر إلى ذلك وإلى مصادر الطاقت المنافست يِّ استراليا، قدر بريان أن أفضل عائد من ون 

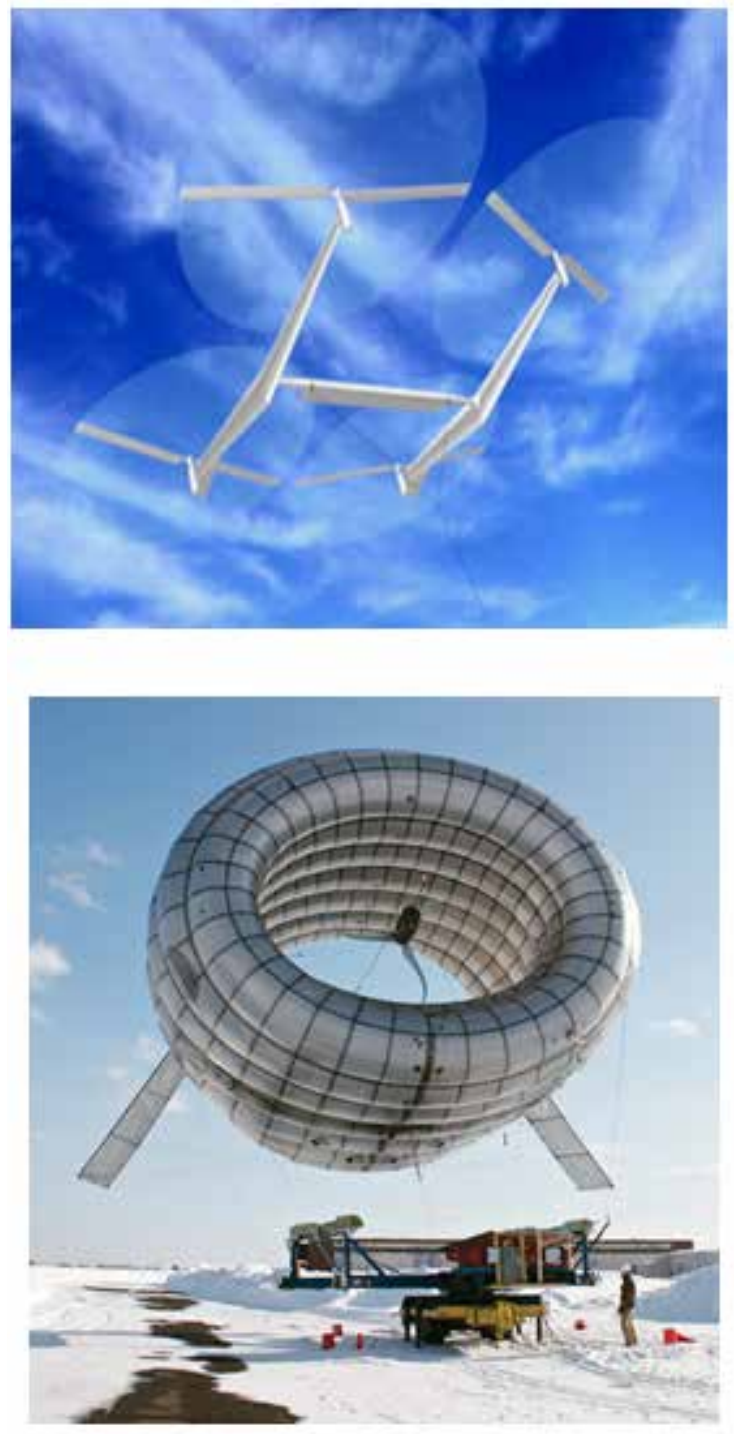

الموقع لا يسمعون هدير المراوح الضخمت وهي مشكلت رئيسيت يعاني منها الناس الذين يقيمون بجوار مزارع الرياح السطحية.

• إذا تعين نقل مزرعت الرياح إلى أي مكان آخر فمن السهولت بمكان نقل المنظومت بأكملها، وتتيح هذه السهولت هِّ نقل مزرعت الرياح الجديدة من تتبع مجرى التيار الهوائي النفاث أثناء تنقله من الثمال إلى الجنوب خلال العام حيث بالإمكان حمل الأجهزة على قطار متجه بعيدا عن العمران، أو جرها بواسطت
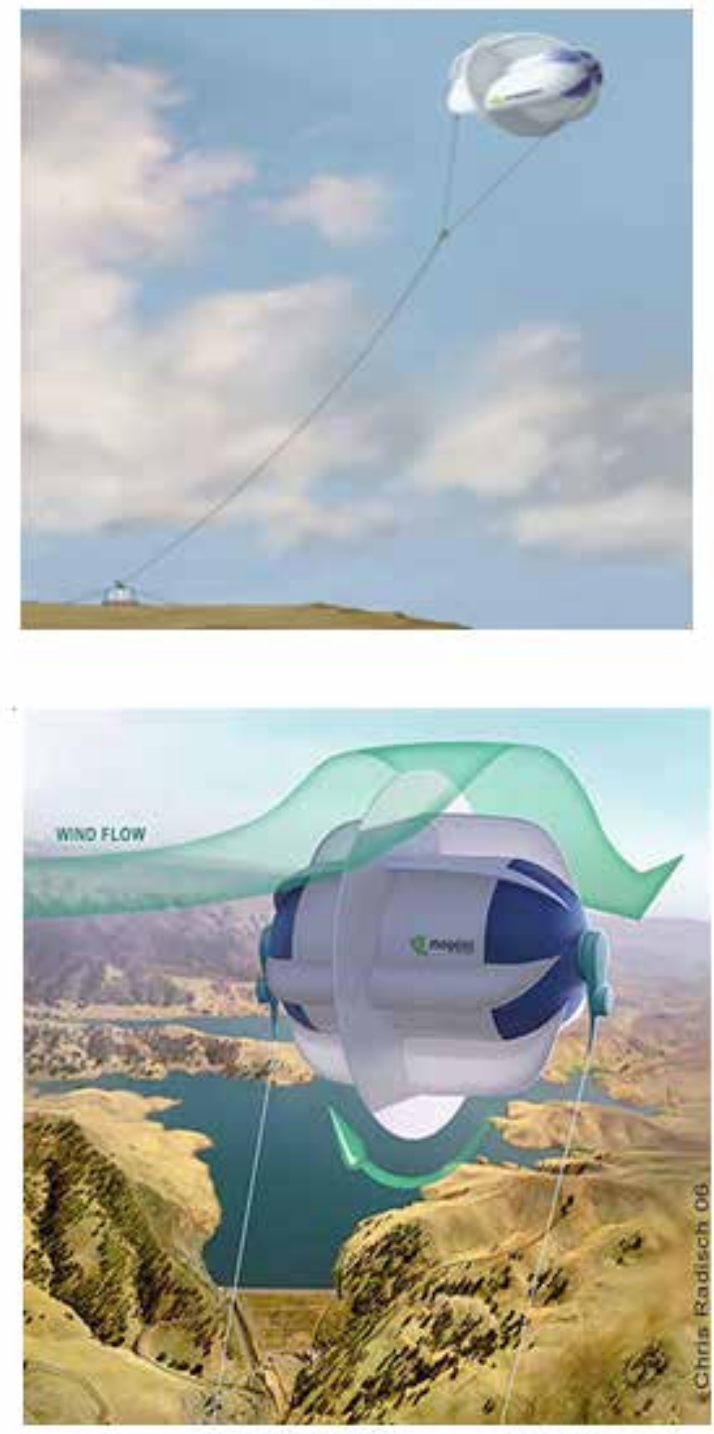

الشكل (2). نماذج للتوربينات الريحيت المعلقت.

3. ميزات مشروع تقنية التوربينات الريحية المعلقة

تشير الدراسات والتقارير العلميتة إلى أن تقنيت

التوربينات الريحيت المعلقت تتميز بعدة مزايا نذكر منها :[12،11،9،1]

• أن إنتاج مزرعت الرياح المؤلفت من عشرة أجهزة

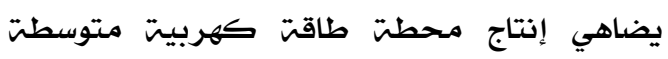
الحجم. • أن إدارة مزرعت رياح عند ارتفاع 4-5 كيلومترات لها ميزة هامت، فالسكان الذين يقيمون بالقرب من هذا 
مجالهم الفضائي، وعلى الرغم من أن الارتفاع الذي يتراوح بين 4 - 5 كيلومترات يعتبر أقل من الارتقاع التطوايِّ بالنسبت لطائرات نقل الركاب النفاثت، فإن سلطت سلامتة الطيران المدني أعربت عن قلقها من هذا المثروع، وبحسب التشريعات الحاليت لا يسهـح بتحليق الأجسام المربوطت لأكثر من مسافت 100 متر فوق مستوى سطح الأرض دون الحصول على تصريح خاص بحيث يتم إضاءتها بصورة ملائمت حتى لا يرتطم بها أي جسهم طائر. من المعروف أن استراليا تعتبر واحدة من أكبر مصدري الفحم يِّ العالم لذا يتوقع بريان بعض المعارضت لمثروعه من قبل أرباب الصناعات الذين لهم مصلحتِ ِِّ الحفاظ على الوضع الراهن. على الرغم من التمويل التدريجي الذي تلقاه مشروع بحث بريان عبر السنوات، فإنه واجه صعوبات الحصول على التأييد الكايِّ للحصول على حقل تجارب لتوربيناته الريحيت الطائرة، فقد قام مكتب البيت الأخضر الحكومي الأسترالي الذي يتعامل مـع المسائل المتعلقت بالبيوت الزجاجيتً برفض الطلب الذي تقدم به بريان لأجل منحه حقلا لتجاربه مشترطا يِ البدايت تجهيز طائرته بالمعدات الكلازمته. عندما حصل بريان على التمويل الكايف، تخيل تصميم طائرة لها مراوح ضخمت يبلغ قطرها 35 مترا قادرة على إنتاج 20 ميجاواط من الكهرباء، واقترح إجراء تجربت بالقرب من موقع إطلاق الصواريخ ِِّ وومبرا بجنوب استراليا حيث يحظر تحليق الطائرات. ويِ حالت نجاح التجربت فإن هذا النوع من الطائرات قد يزود مناطق شاسعت بالكهرباء، ولكن حتى لو سمح لبريان باختبار أجهزته يِّ الأجواء العليا فثمت مشاكل أخرى قد تحطم أحلامده، حيث يشير المسؤولون الأستراليون إلى وجود قانون بشأن الحد الأقصى من الطاقت التي يتهم توليدها من المراوح الدوارة، والأهم من ذلك هناك مسألت المصداقيت بشأن نسبت تكاليف البناء
سفينت لتوجيهها بشكل دائم أسفل التيار النفاث. على الرغم من أن طاقت التيارات النفاثت لا تتطلب أن تكون التوربينات الريحيت ضخمت الحجم وثقيلت الوزن كحال توربينات الرياح الأرضيت التي تقام على سفوح التلال المكشوفت أو ِِِ الجزر والتي غالبا ما تتعرض لضربات الرياح العاتيت ما يعرض أجهزتها الميكانيكيت للاهتر اء، فإن الرياح التي تهب على ارتفاعات شاهقت أكثر ثباتا وحتى عندما تكون هوجاء فبإمكان التوربينت تسلقها فترتفع وتهبط فيها كالطائرة الورقيت بدل أن تقف وراءها بصلابت، هذه الحركت تقلل القوى المؤثرة على المراوح والأجهزة الميكانيكيت. يؤكد الخبراء أن الإجهاد المعدني سوف يكون أقل تأثيرا لذا يعتقدون أنه بالإمكان صنع التوربينات الريحيت هذه بصورة أخف وأكثر واقعيت من توربينات الرياح الأرضيت.

عندما تحتاج توربينات الرياح إلى إجراء بعض الصيانت عليها أو يخ حالت تعرضها لتهديد الرياح العاتيت بالإمكان إعادتها إلى الأرض ومن ثم إرسالها إلى الجو مرة أخرى بعد صيانتها أو بعد هدوء العاصفتة. بالإمكان جعل المولدات الكهربيت تعمل بصورة معاكست أي نقل خطوط الطاقت الأم عبر الأسلاك لإدارة المراوح الموجودة ِِّ هذه المولدات، إذ بالإمكان التحكم بالمحطت الهوائيت بصورة شبيهت بالتحكم بالهليوكبتر الكهربيت، ويمكن استخدام هذه الوسيلت

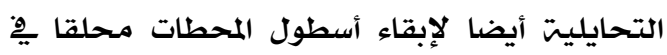
الأجواء العليا خلال الفترات القصيرة من سكون الرياح، كما أنه خلال الفترات الطويلت من سكون الرياح التي تمتد ثلاثين ساعت أسبوعيا يِّ المتوسط، يمكن إنزال

$$
\text { ألتوربينه الريحيت على الأرض. }
$$

\section{4. الصعوبات التي يواجهها المشروع}

على الرغم من أن الاحتمالات الكبيرة التي تتوقع إمكانيت توفير طاقت نظيفت غير محلددة صديقت للبيئت بواسطت هذه التقنيت، فلا يبدو أن المجتمع الأسترالي مقتنع بفكرة بريان، حيث إن هنالك عدة نقاط لازالت تحتاج للتوضيح مثل: قد لا تحظى أجهزته برضا الطيارين لأنها تتعدى على 
لا تنجح على الكواكب الأخرى؟ وعلى هذا الأساس قدم بريان لوكالت الفضاء الامريكيت (ناسـ) اقتراحا يشير إلى أن أجهزته سوف تكون ملائمت لحساب الطاقت من التيار الهوائي النفاث لكوكب المريخ خلال المهام الفضائيت لاستكثاف الكوكب الأحمر. وباكتمال معظم مشاريعه يركز بريان على إثبات نجاح مشروعه و أنه مربح ماديا. ويضيف هذا دعما جديدا لأنصار طاقت الرياح حيث تشير تقارير المجلس العالمي لطاقت الرياح أنه خلال سنت 2005 تم تركيب معدات توليد طاقت الرياح ِِّ أكثر من 30 دولتة بلغ مجموع القدرة التي تنتجها 11,531 ميجاوات، وهذا يمثل زيادة يخ الأساس السنوي بنسبت 40.5 \%، وزيادة ٌِِ النمو التراكهي بنسبت 24 \% [13]. والجدول الآتي يبين أن طاقت الرياح السطحيت قد أصبحت قادرة فعلا على تأمين دخل ذي دلالت يْ مجال توليد الكهرباء الخاليت من الكربون [14]. فماذا عن حجم الدخل الذي يمكن تأمينه ِِِ حالت نجاح مشروع استثمار

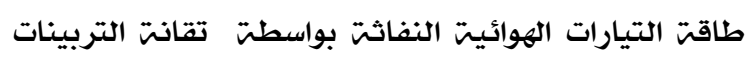
الريحيت المعلقت؟ الميات
إلى النتأُج وهي مسألت خاسرة قد تقضي على المثروع.

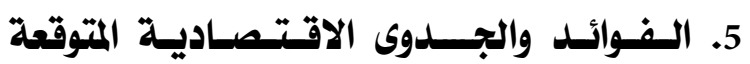
للمشروع

على الرغم من كل الصعوبات التي يواجهها هذا المشروع فإن بريان لا يزال واثقا من نجاح مشروعه، فقد أنهى دراست تحليليت بالنسبت لمزايا التكلفتة وتظهر هذه الدراست بأن العائد الاستثماري للتوربينت الريحيت التي تولد خمسين كيلوواط من الكهرباء سوف يكون صغيرا، أما التوربينت الكبيرة فقد تسد نفقات تكلفتها يِّ غضون سنوات قليلتة. وبالرغم من أن الهدف الرئيسي لبريان هو استخدام التوربينات الريحيت المعلقت لتوليد الطاقت الكهربيتة، فإنها مـا أن تصبـح فعالت حتى يمكن تسخيرها كما يقول يِّ مجالات الاتصالات أو عمليات الاستطلاع الجوي لأن لديها مدى رؤيت واسعا يصل إلى مئتي كيلومتر، ويمكن استخدامها كذلك للتخلص من 95 \% من أبراج الهواتف النقالت يِ تلك المناطق. وإذا ما نجحت التجارب على الأرض فلماذا

جدول (1). القدرة العالميتة التراكميت والسنويت لطاقت الرياح.

\begin{tabular}{|c|c|c|c|c|c|c|c|c|c|c|c|c|}
\hline 2006 & 2005 & 2004 & 2003 & 2002 & 2001 & 2000 & 1999 & 1998 & 1997 & 1996 & 1995 & 1995 - الفترة الزمنيتة 2006 \\
\hline 74,223 & 59,091 & 47,620 & 39,431 & 31,100 & 23,900 & 17,400 & 13,600 & 10,200 & 7,600 & 6,100 & 4,800 & 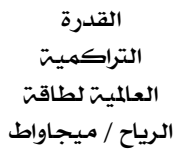 \\
\hline 15,197 & 11,531 & 8,207 & 8,133 & 7,270 & 6,500 & 3,760 & 3,440 & 2,520 & 1,530 & 1,280 & 1,290 & العالمدرة السنويتة الطاقت \\
\hline
\end{tabular}

نتيجت اصطدامها ونتيجت التسخين الشديد، عند وصولها إلى حدود التروبوبوز (الطبقت الانتقاليت التي تفصل بين طبقتي التروبوسفير والستراتوسفير) تنقسهم إلى قسمين قسم يتجه شمالا والآخر يتجه جنوبا، حيث إن التروبوبوز يعمل مثل الدرع الذي يقوم بهنع الهواء الساخن المتصاعد من سطح الأرض من الاستمرار بالتصاعد، ونتيجت اختلاف

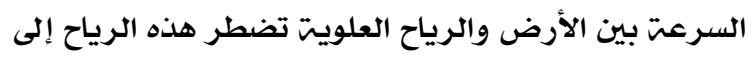
الهبوط، أي أن أغلب الهواء الصاعد بمنطقت الحزام الاستوائي لا يقطع كل الرحلت حتى يصل إلى المنطقت القطبيتة وعوضا عن ذلك فان جزءا كبيرا منه يهبط تجاه سطح
6. فكرة عامة حول تطور اكتشاف الدورة النمطية للغلاف الجوي

منذ القرن الثامن عشر تم الحصول على المزيد من المعلومات عن الرياح السطحيت والرياح العليا، وعليه فقد أصبح معروفا ِِ الوقت الحاضر أن الرياح التجاريت تهب من مناطق الضغط العالي شبه المداري يِّ نصفي الكرة إلى منطقت الضغط المنخفض عند خط الاستواءو، وتلتقي الاسي الرياح الشماليت الشرقيت الهابت من النصف الشمالي مع الرياح الجنوبيتة الشرقيت الهابت من النصف الجنوبي

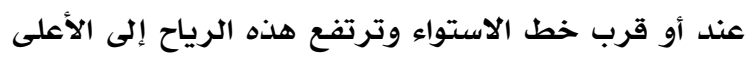


القطبيت فتدعى خليت فيرل نسبت إلى مكتشفها عالم الأرصاد الجويت الامريكي ويليام فيرل، وهي تعتبر خليت غير مباشرة نظرا لأن حركتها معاكست للقوانين Indirect Cell الطبيعيت المباشرة، حيث إن الهواء الدايِّء الأقل كثافت بها

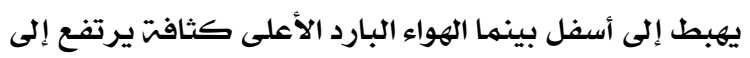

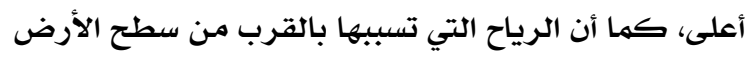

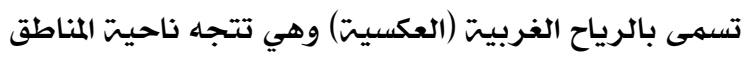
القطبيتة. مكونات هذه الخليتة غير مستقرة من حيث الحجم واتجاه الرياح؛ حيث إن أنظمت الضغط فيها متحركت، والرياح بها متقلبت. ويظهر بين حدود هذه الخليت والخليت القطبيت تيار هوائي سريع يسمى التيار القطبي النفاث؛ كما يظهر بينها وبين خليت هادلي التيار النفاث شبه المداري [16] Subtropical Jet Stream مقطعيا لبنيت الدورة العامت للهواء الجوي ويبين مواقع التيارات الهوائيت النفاثت القطبيت والشبه مداريت.
الأرض وذلك عند دائرة عرض 30 درجت ويتحرك هذا الهواء الذي هبط ثانيت تجاه خط الاستواء على صورة رياح تجاريت مكونا جزءًا من خليت كبيرة من خلايا الحمل، هذه الخليت المتكونت من الرياح السطحيت والرياح العليا والتيارات الصاعدة فوق خط الاستواء والتيارات الهابطت فوق دائرتي عرض 30 • شمالا وجنوبا تسمى خليت هادلي [15]، إضافت إلى خليتين أخريين هما خليت فيرل والخليت القطبيت. الخليتة القطبيت مماثلت لخليتة هادلي وهما تسميان بالخلايا المباشرة Direct Cells نظرا لأن حركت الهواء بهما تتوافق مع قوانين الطبيعت المباشرة من حيث ارتفاع الهواء الساخن إلى أعلى وهبوط الهواء البارد إلى أسفل. تقع

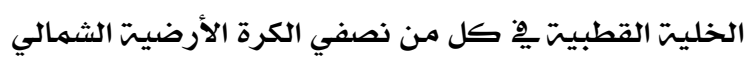
والجنوبي بمناطق العروض العليا والقطبيت بين دائرتي عرض 60 و 90 •وهي تشبه خليت هادلي لكنها تجري على مقياس أصغر. أما الخليت التي تقع بين خليت هادلي والخليت

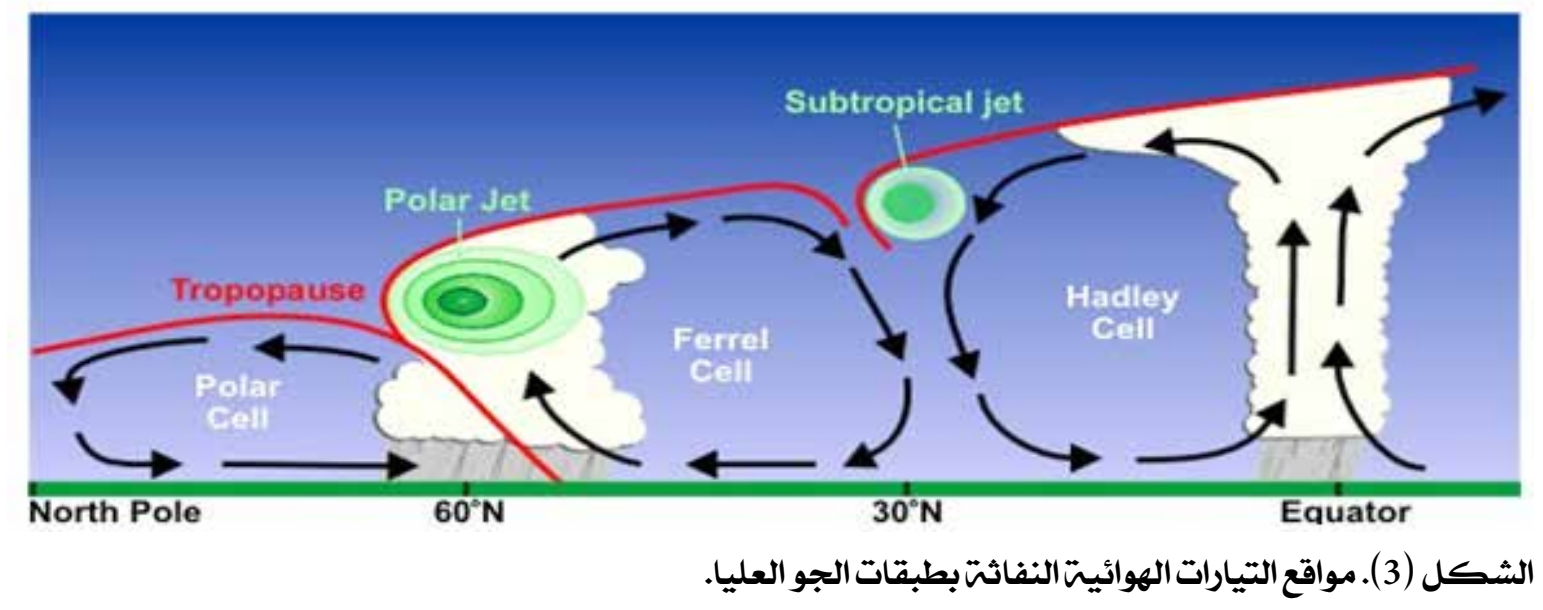

البحريتاليابانيت. كما لاحظ رجال السلاح الجوي الأمـريكي وجوده خلال الحرب العالميت الثانيت أيضا اثناء طيرانهم فوق الجزر اليابانيت على ارتفاع 30 الف قدم، وقدرت سرعت هذه التيارات حينئذ بنحو 200 - 300 ميل/ساعت، ووضعت نظريته من قبل مدرست الأنواء الجويت يِ شيكاغو[17]. ويساعد يْ نشوء التيارات الهوائيت النفاثت التباين الحراري الشديد بين أجواء العروض الدنيا والعروض الوسطى، حيث تتناقص درجت الحرارة بشدة باتجاه القطبين. ونتيجت لذلك يتشكل فوق هذه العروض مِّ كل من نصفي الكرة الأرضيت الشمالي والجنوبي تيار هوائي على شكل نطاق ملتو يتجه من الغرب إلى الشرق، يتحرك بسرعت هائلت تتراوح بين

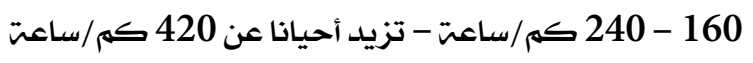

ولا تتوقف دراست حركت الهواء ٍِِ الغلاف الجوي على الدورة العامت للرياح السطحيتة، إذ ينبغي دراست حركت الهواء فِ الطبقات العليا للغلاف الجوي، حيث تساهم هذه

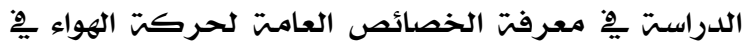
طبقات الجو العليا وعلاقت ذلك بها يحدث له بالقرب من سطح الأرض. وقد أكدت الدراسات الحديثت وجود تيارات هوائيت على ارتفاعات عاليت بطبقت التروبوبوز تتميز بشدة سرعتها، وتبعا لشدة سرعتها (Tropopause) تعرف هذه الرياح باسم التيارات النفاثت (Jet Streams). أول من اكتثف التيارات الهوائيت النفاثت هو الياباني واشبورا اويشي Washbura Ooishi عام 1920 أثناء الحرب العالميت الثانيتة وتم شرحه هٌِ باديء الأمر من قبل 


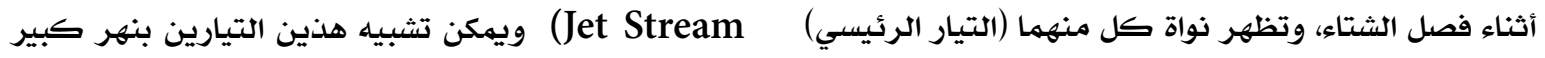

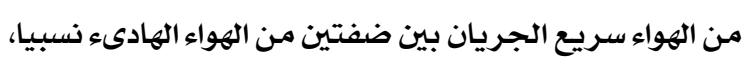

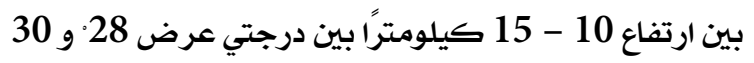
وتتكفل هذه التيارات النفاثت بمعظم عمليات نقل الطاقت إلى

درجت شمالا وجنوبا. ويعرف كل من هذين النفين التيارين بالتيار

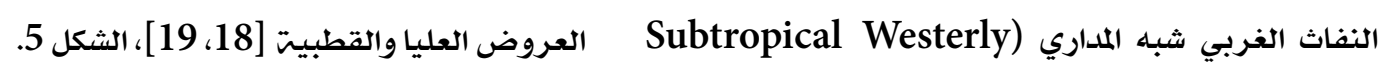

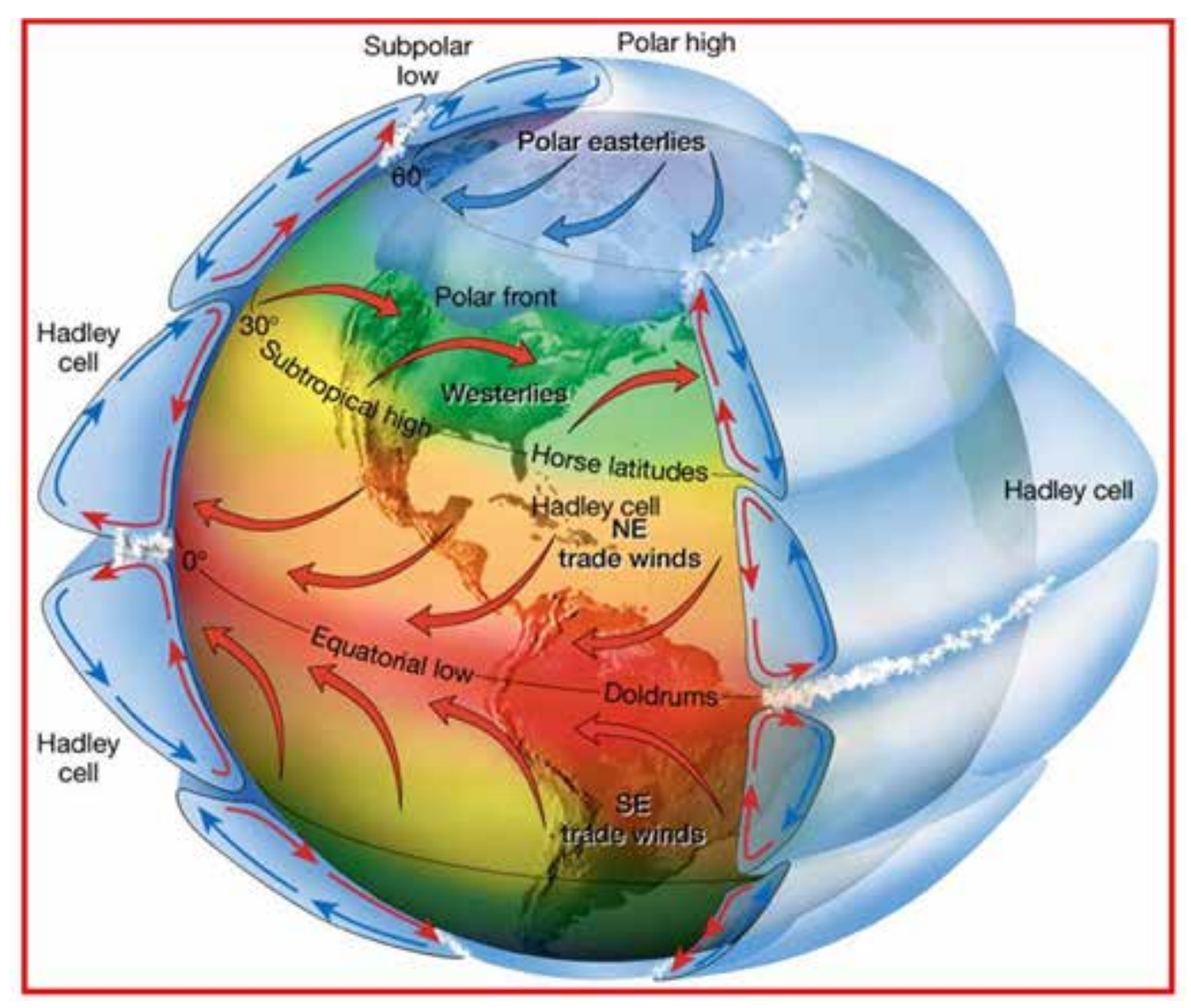

الشكل (4). الدوران العام للغلاف الجوي للأرض.

ويكتسب التيار النفاث سرعته من الفروق الحراريت بين

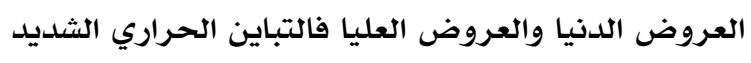

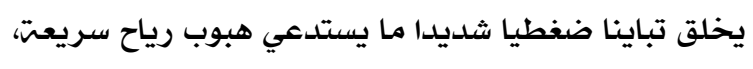

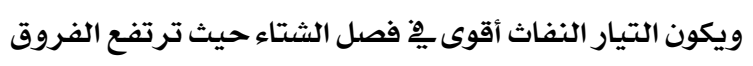

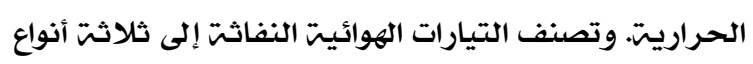

هي:

التيار النفاث شبه المداري: يتكون من الرياح الغربيت

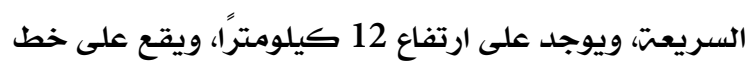

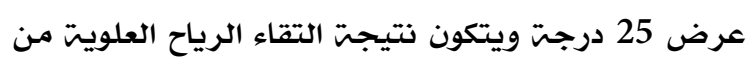

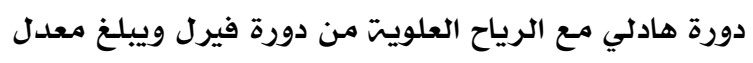

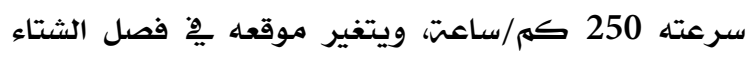
والصيف وله تأثير كبير على الأحوال الجويت.
7. التيارات الهوائية النفاثة

هي عبارة عن حزام أو مجرى ضيق من الرياح السريعت

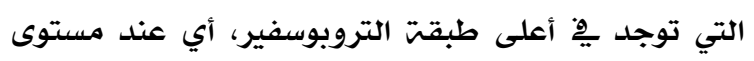

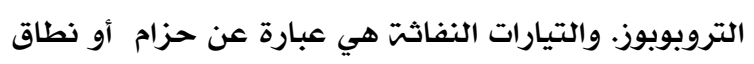

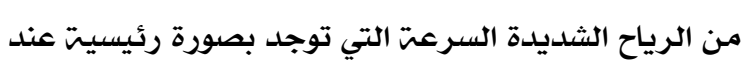

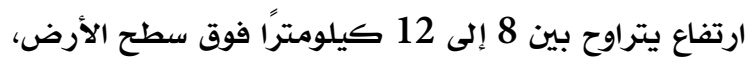

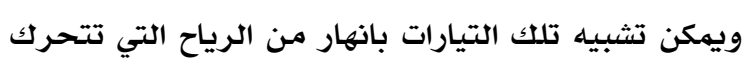
بشكل عام من الغرب إلى الشرق، ويصل طولثها إلى عدة آلاف من الكيلومترات ويتراوح عرضها بين 500 إلى 650 كيلومترا، ويزيد سمك التيار الواحد منها عن 1000 متر.

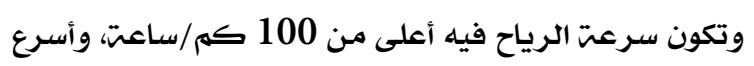

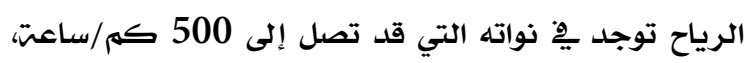


التيار النفاث المداري: يتكون من الرياح الشرقيت فوق

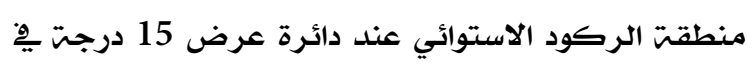
فصل الصيف بالنصف الشمالي للأرض، والتيار النفاث المداري ضعيف مقارنت بالتيارات النفاثت الأخرى حيث تصل الفيفل أقصى سرعت له 180 كم /ساعتة.
التيار النفاث القطبي: يعتبر من أكثر ظواهر الدورة الجويت العليا أهميتة وهو عبارة عن رياح غربيت تتكون بهنطقت التقاء الرياح العلويت من دورة فيرل مـع الرياح العلويت من الدورة القطبيت. وتصل سرعته إلى

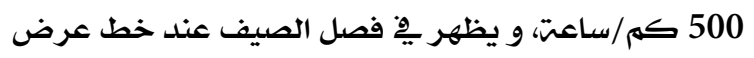

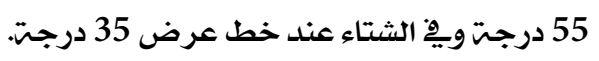

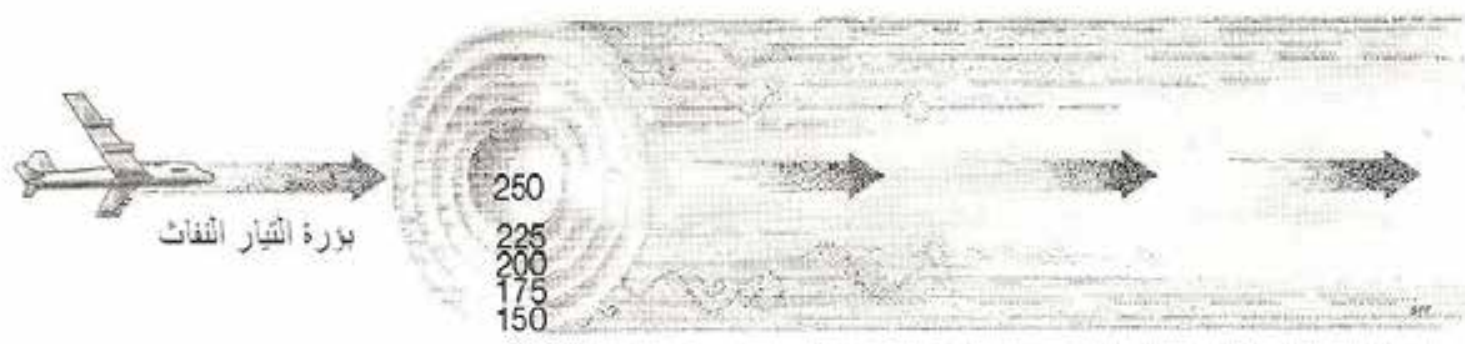

الشكل (5). مقطع توضيحي لمجرى التيار النفاث وتبلغ سرعت الرياح في بؤرة التيار 250 عقدة ثم تقل تدريجيا بالابتعاد عن قلب أو بؤرة التيار.
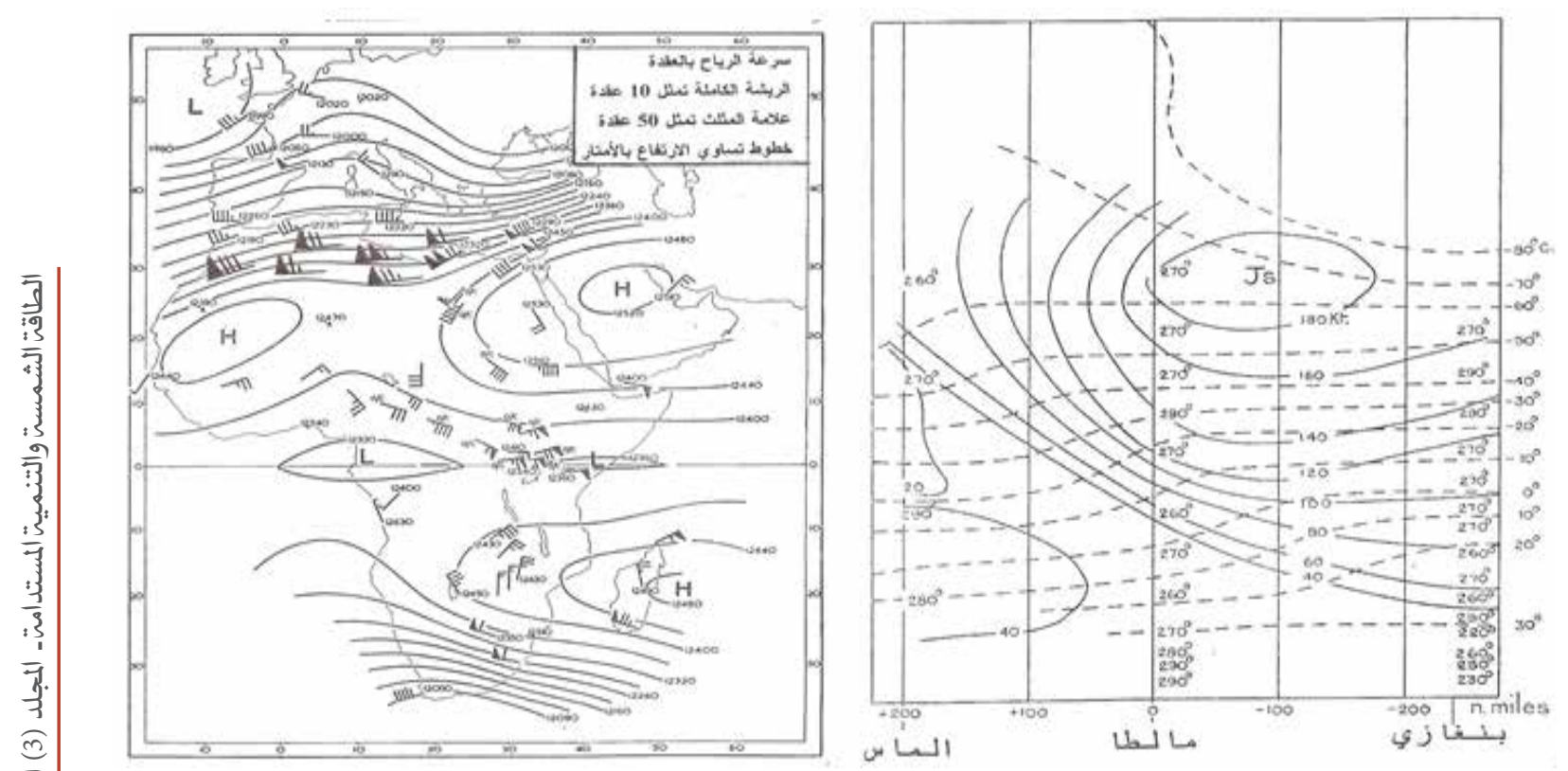

$$
\text { الشكل (6). مقطع رأسي [20]، ومقطع أفقي [21] للتيار النفاث الشبه استوائي. }
$$

النفاثت وذلك على أساس اتباع أسلوب التحليل السينوبتيكي الذي يمر عبر تنفيذ سلسلت من الخطوات على النحو التالي: رصد البيانات: تقوم محطات الأرصاد الجويت الخاصت بالأجواء العليا باستخدام جهاز الراونسوند Rawinsoundes
8ـ السمات والخصائص السينوبتيكية للتيارات الهوائية النفاثة بالأجوائ الليبية الئية

للوقوف على الخصائص السينوبتيكيت للتيارات الهوائيت النفاثت بالأجواء الليبيت تم الاعتماد على متابعت الأوضاع الجويت التي تكررت فيها الحالات المؤثرة للتيارات الهوائيت 
عند الساعت 0000 توقيت عالمي والثانيت عند الساعت 1200 توقيت عالمي، يحتوي الجهاز على وحدة إرسال راديويت تمكنه أثناء مروره بطبقات الجو العليا من إرسال الإثـارات التي تم رصدها إلى الأرض، وتتولى أجهزة استقبال خاصت استلام

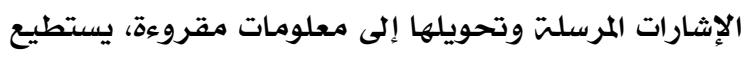

الجهاز الوصول إلى ارتفاع يتراوح بين 27 و 42 كيلومترًا.
كبير معباً بغاز الهيدروجين، وهو عبارة عن جهاز إلكتروني صغير يستخدم لرصد خصائص المقطع الرأسي للغلاف الجوي وهو مزود بهجسات خاصت لاستشعار ورصد سرعت واتجاه الرياح النفاثت وارتفاعها عن سطح الأرض إضافت إلى لى بعض العناصر الأخرى كلدرجت الحرارة والرطوبت. يطلق

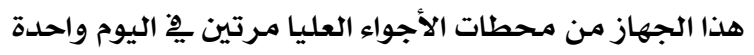

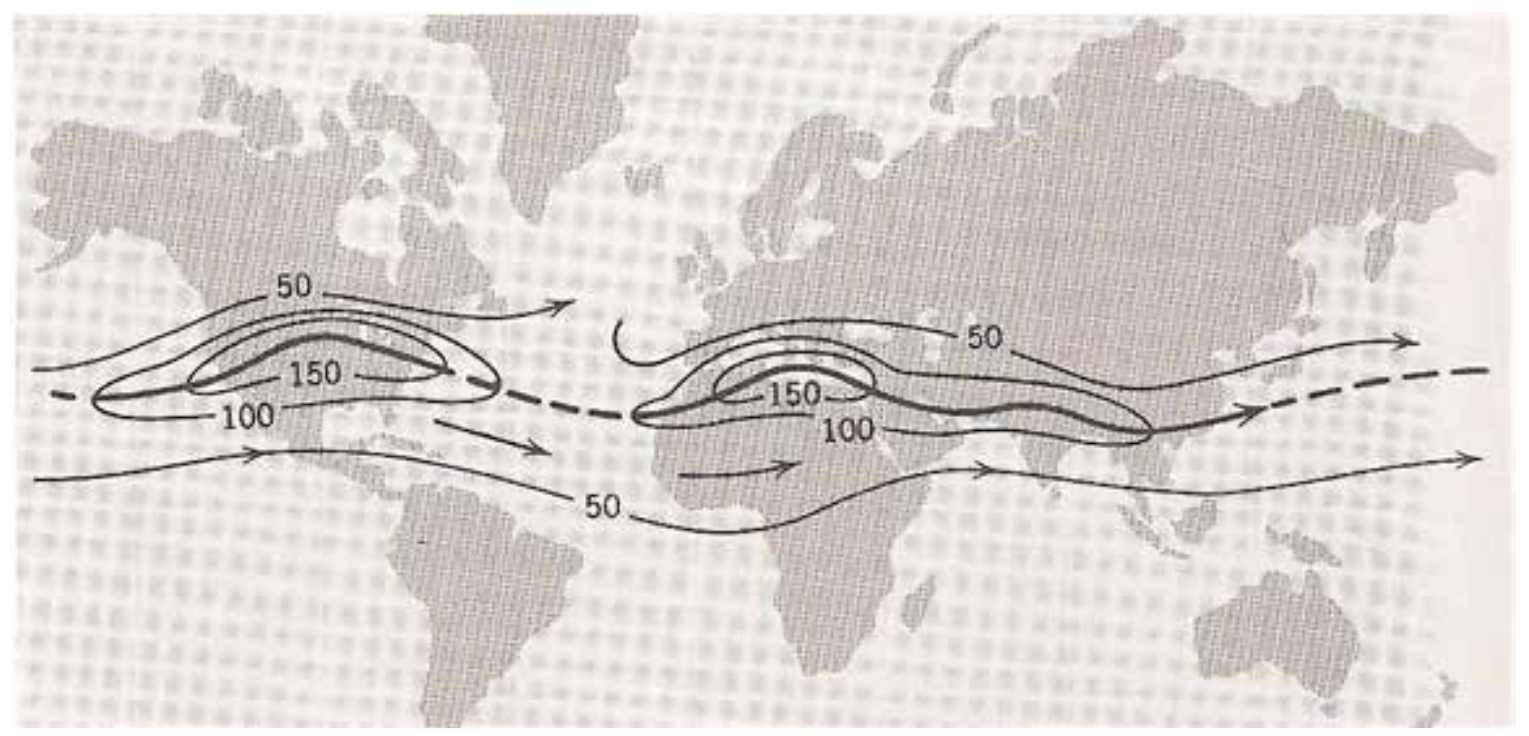

الشكل (7). حزام التيارات الهوائيت النفاثت على المناطق الشبه استوائيت بشكل عام وعلى مناطق شمال ووسط ليبيا بشكل خاص، الخطوط المتصلت تمثل سرعت الرياح بالعقدة [22].

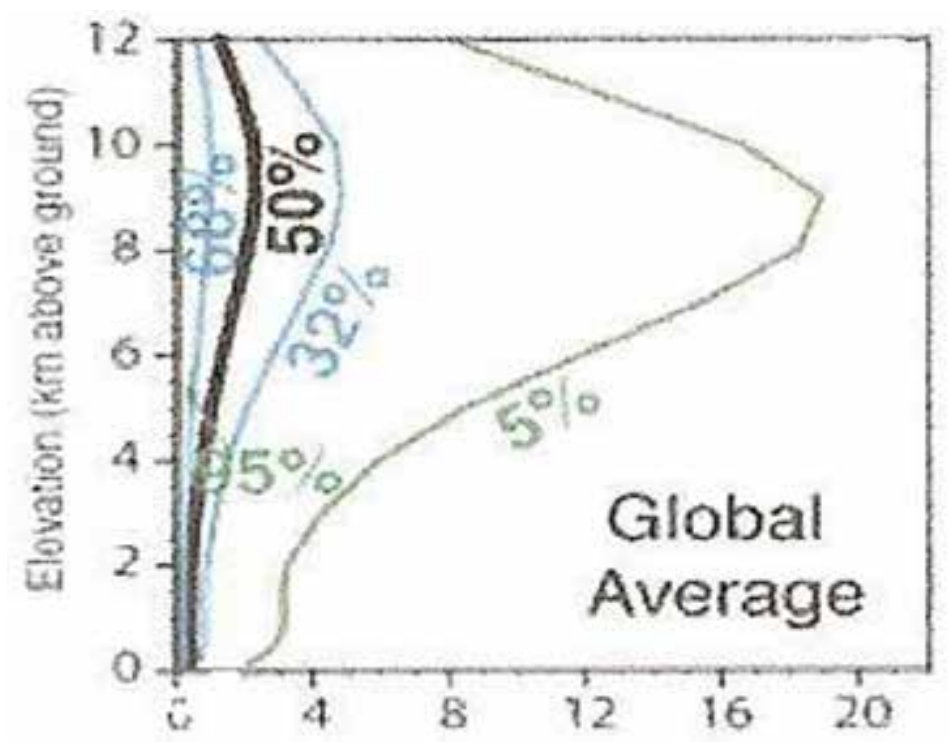

الشكل (8). المتوسط العالمي لكثافتشاقتالرياح (كيلوواط/ متر مربع) كدالتّفي الارتفاعالتي تجاوزت 50 \%، 68 \%، . 

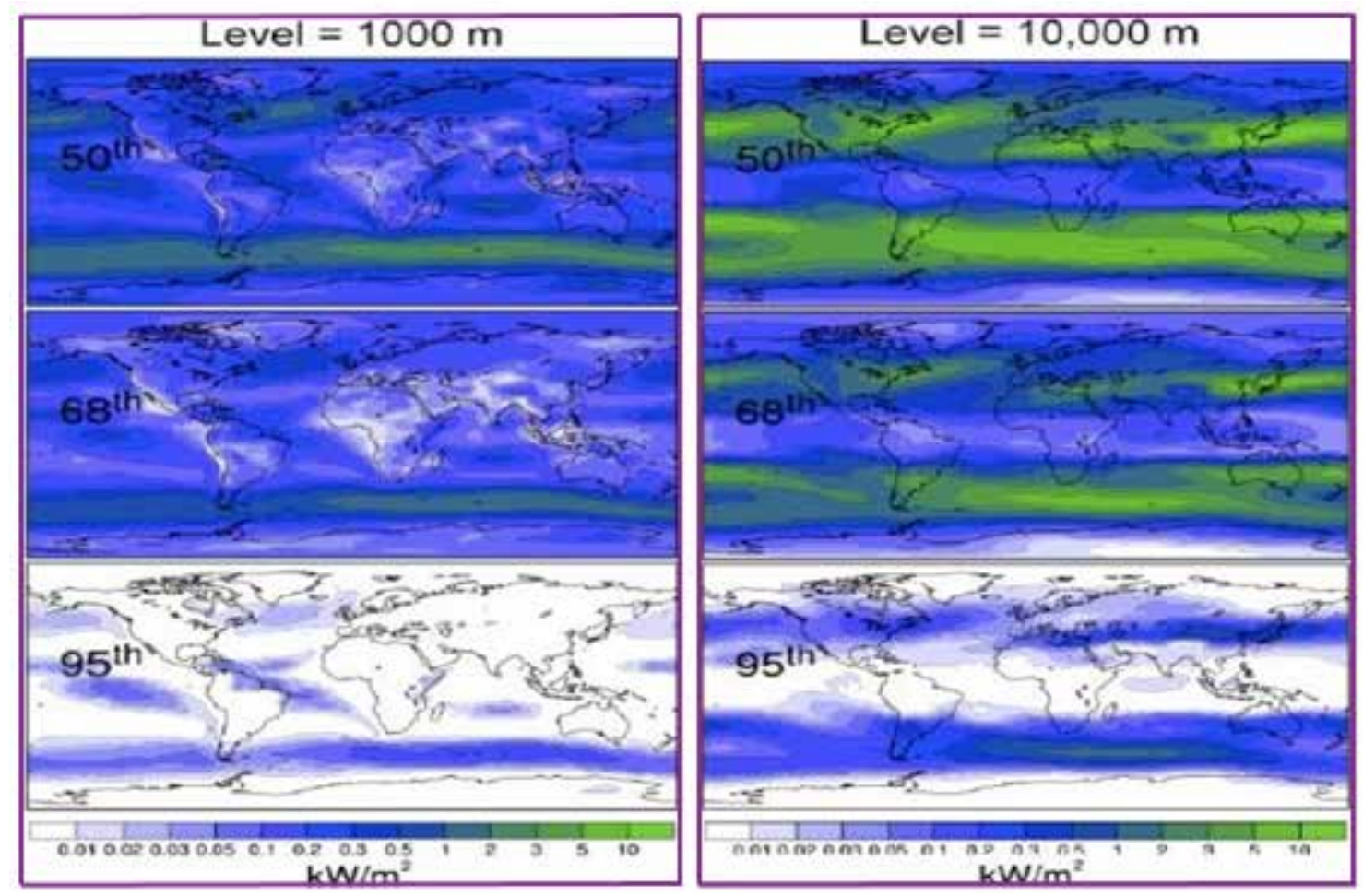

الشكل (9). كثافتّطاقت الرياح (كيلووات/ متر مريع) التي تجاوزت 50 \%، 68 \%، 95 \% من زمن فترة الدراست 1979.

2006 على الإرتقاعين 1000 متر و 10000 متر [23]، [24].

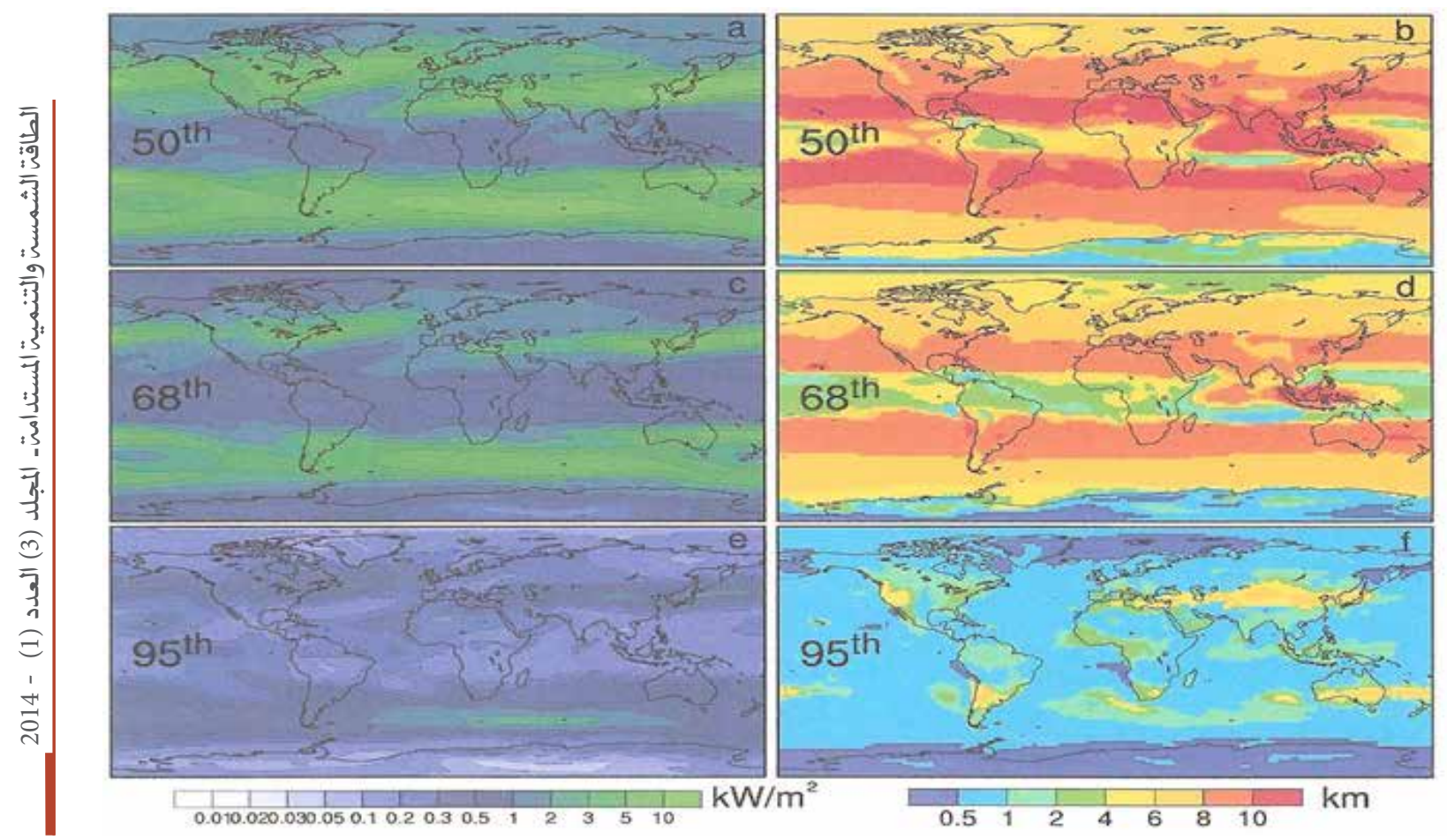

الشكل (10). الكثافت المثاليت لطاقت الرياح (كيلوواط/ متر مربع)، الارتفاع المثالي (كلم)، التي تجاوزت 50 \%، 68 \%؛

95 \% من زمن فترة الدراستـ_1979 2006، [24]. 
واتجاه الرياح موضوع الدراستة، وتحتوي هذه الخرائط على آلاف النقاط تمثل كل منها موقع محطت رصد، تسهى هذه الخرائط عادة باسه الخرائط (السينوبتكيت) وهذه الكلمت تعني الخرائط التي يتم رسمها يِّ وقت واحد، وتشمل المنطقة التي تغطيها هذه الخريطت معظم الدول الأوروبيت وإفريقيا وغرب آسيا، أي من عند خط طول 5 غربا إلى خط طول 35 شرقا ومن خط عرض 15 شمالا إلى خط عرض 50 شمالا. تحليل البيانات: فور الانتهاء من عمليتالتوقيع تخضع تلك الخرائط إلى التحليل حتى تسهـح بالحصول على إيضاح بياني لمجال سرعت الرياح النفاثت بوحدة العقدة واتجاهها بالدرجتة ويعرف هذا بتحليل خطوط تساوي السرعت بوحدة العقدة. وتتكون خريطت متساويات السرعت من خطوط تصل النقاط ذات السرعات المتساويت للرياح. يعرف خط تساوي السرعت (بمتساوي السرعت Isotach)، وهي تبدأ عادة برسهم الخط الذي يمثل 60 عقدة تليه الخطوط 70 و80 و90 عقدة وهكذا إلى غايت أعلى سرعت تم رصدها، الشكل 11 يعطي فكرة عن كيفيت رسهم خطوط تساوي سرعت الرياح.
تجميع البيانات: تتجمع الرصدات التي تم إجراؤها على المستوى الوطني بالمقر الرئيسي للمركز الوطني للأرصاد الجويت الذي يقوم بلدوره بإبراقها إلى المراكز الإقليهيت الدوليت التي تعمل كحلقت وصل بين المراكز الوطنيت لكافت البلدان الأعضاء بالمنظمت العالميت لكلأرصاد الجويتة تعمل المراكز الإقليميت على ضخ المعلومات إلى المراكز العالميت التي بلدورها تقوم بإرسال كل البيانات التي تجمعت بها إلى المراكز الوطنيت، وقد قامت المنظمت العالميت

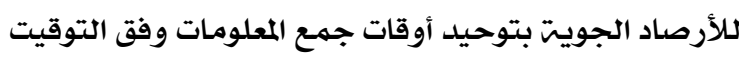
العالمي الموحد. إن طريقت إرسال هذا الكم الهائل من المعلومات تتم بطريقت سهلت وسلست، حيث تم وضع لغتت عالميت مشفرة تستخدم أرقاما ورموزا متفق عليها. توقيع البيانات: بعد تجميع المعلومات والبيانات تأتي خطوة الاستفادة منها، وذلك يبدأ من خلال تنظيهها وتوقيعها على خرائط، وهذه الخرائط تغطي أصنافا مختلفت من المعلومات الرصديت فبعضها يعالج مستويات الضغط الجوي بقيم مختلفت، والآخر يتعلق بلرجات الحرارة، وسرعت

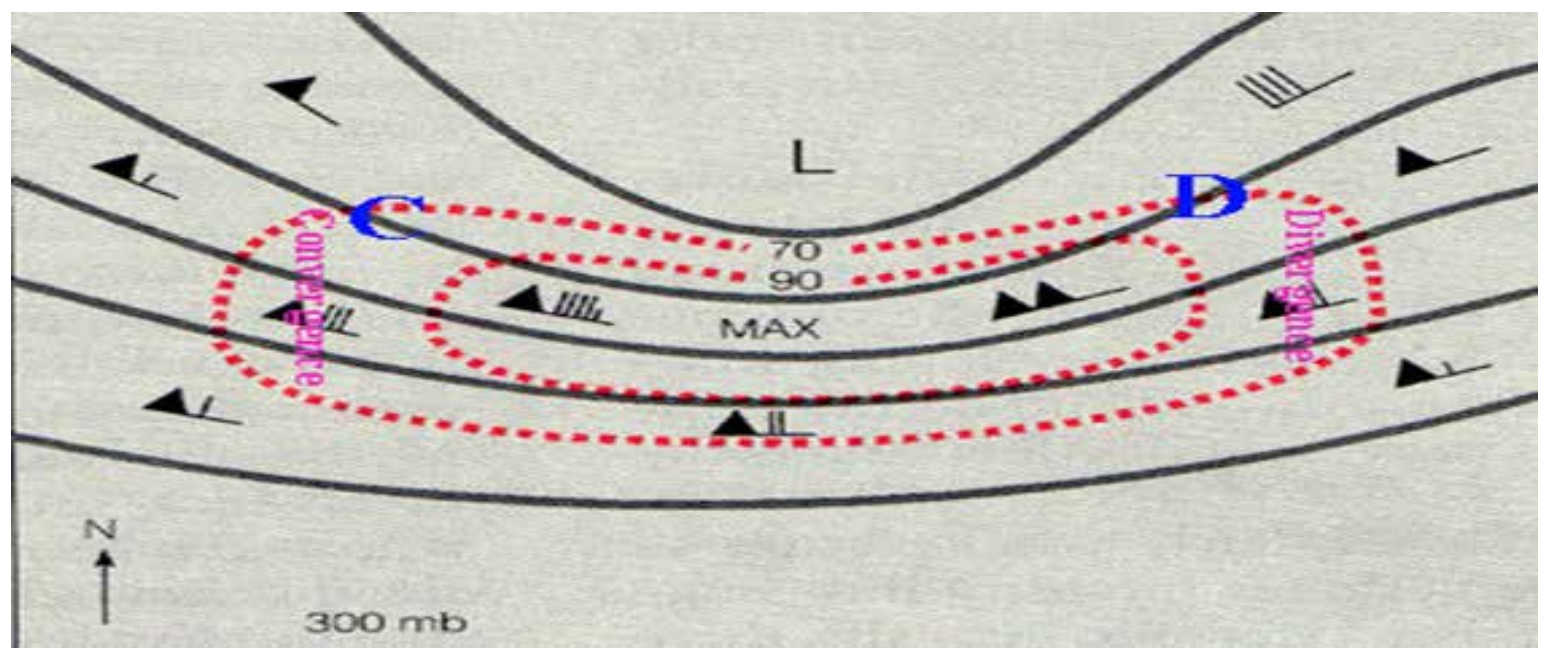

الشكل (11). نموذج يبين كيفيتّ توصيل خطوط تساوي سرعت الرياح.

واتجاه الرياح النفاثت والارتفاعات التي وجدت عليها لفترة 60 شهرا متتاليا، إبتداءا من (01 يناير 2003)، حتى (31) ديسمبر 2007)، الشكلان 12 أ، 12 ب، يبينان نموذجا لتلك الخرائط، ويمكن من خلال هذا الشكل التعرف على حزام الرياح النفاثت الذي ظهر ِِّ الأجواء الليبيت خلال يوم 20 يونيو 2005 ميلاديت.
تصنيف وترتيب البيانات موضوع الدراستّ: تم

الاعتماد على استخدام منظومت سينرجي SYNERGIE كمصدر للبيانات والمعلومات والتحليل، وهي منظوهـت تستخدم لتحليل وتنسيق وعرض الخرائط الخاصت بالأرصاد الجويت حيث تمكن المركز الوطني لكلأرصاد الجويت بليبيا من اقتناء هذه المنظومته منذ سنت 2000 مياديتة وتم القيام بتصنيف الخرائط الدالت على سرعت 


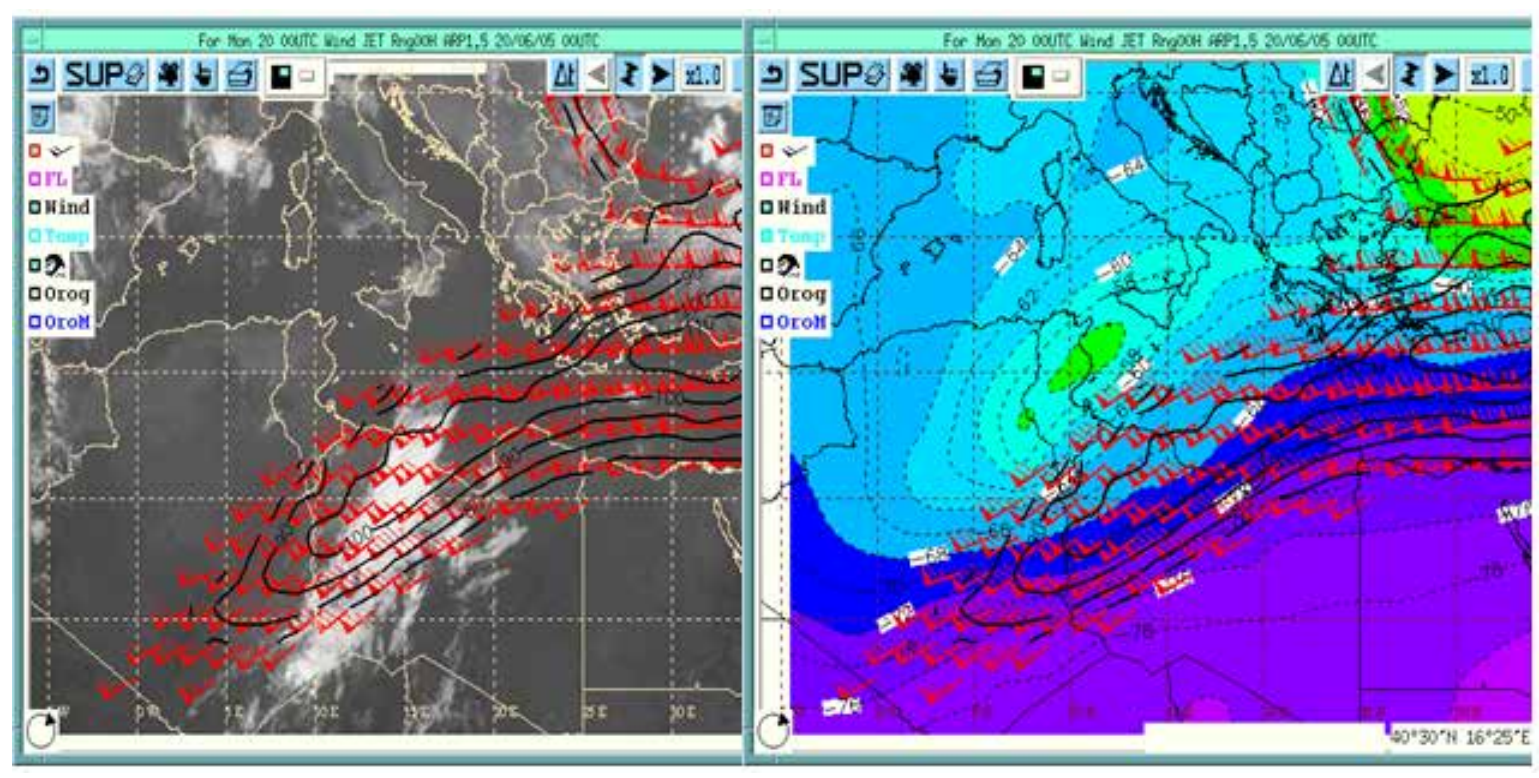

$$
\begin{aligned}
& \text { الشكل (12 ب) } \\
& \text { الشكل (12 أ) }
\end{aligned}
$$

الشكل (12 أ). خريطتسينوبتيكيت تظهر حزام الرياح النفاثت ومناطق التبريد والتسخين الهوائي المرافقت لها.

$$
\text { الشكل (12 ب). صورة القمر الصناعي لخلايا السحب المترافقتمع حزام الرياح النفاثت. }
$$

من بدايت شهر يوليو حتى أواخر شهر أكتوبر، حيث

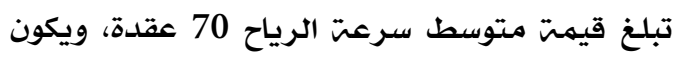
اتجاهها السائد جنوبي غربي، وتظهر عند ارتفاعات

$$
\text { تصل إلى } 12500 \text { متر. }
$$

3. تمتد المساحت الأفقيت التي يغطيها التيار النفاث من

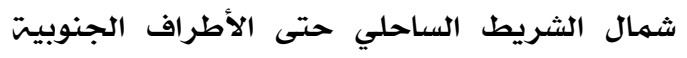

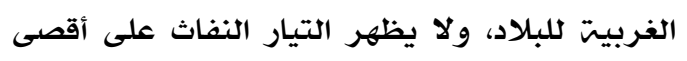
الجزء الجنوبي الشرقي من الأراضي الليبيت إلا نادرا.
ومن خلال تحليل ومتابعت تلك الخرائط [25]، تم

$$
\text { التوصل إلى الاستنتاجات الآتيت: }
$$

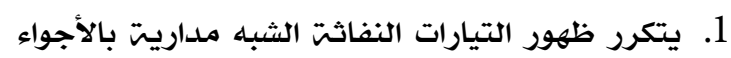

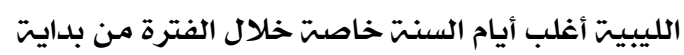

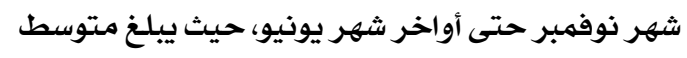
سرعت التيارات النفاثت 120 عقدة، ويكون الاتجرياه

\begin{tabular}{|c|c|c|c|}
\hline \multicolumn{2}{|c|}{ خصائص الفترة التي تنخفض فيها قوة التيار النفاث } & \multicolumn{2}{|c|}{ خصائص الفترة التي تشتد فيها قوة التيار النفاث } \\
\hline من بدايت يوليو حتى أواخر أكتوبر & الفترة الزمنيتي & من بدايت ذوفمبر حتى أواخر يونيو & الفترة الزمنيتي \\
\hline 70 عقدة & متوسط السرعت & 120 عقدة & متوسط السرعت \\
\hline جنوبي غربي & 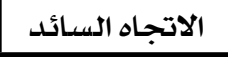 & غربي & 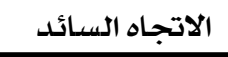 \\
\hline 12500 متر فوق مستوى سطح البحر & متتوسط الارتفاع & 12000 متر فوق مستوى سطح البحر & متوسط الارتفاع \\
\hline شمال الشريط السـاحلي إلى الأطراف & المساحت الأفقيت & من شمال الشريط الساحلي إلى الأطراف & المساحت الأفقيت \\
\hline
\end{tabular}
السائد لها هو الاتجاه الغربي، ويصل متوسط مستوى الناتئ الارتفاع الذي تظهر عنده إلى 12000 متر. 2. تنخفض قوة التيارات النفاثت قليلا خلال الفترة الممتدة

جدول(2). السمات والخصائص السينوبتيكيت للتيارات الهوائيت النفاثت بالأجواء الليبيت. 
اتباع قواعد ولوائح رصد العناصر الجويت الصادرة عن المنظمت العالميت للأرصاد الجويتة.

إن أجهزة القياس بمحطت الرصد خضعت خلال تلك الفترة وبصورة دوريت للهعايرة والصيانت، إضافت إلى خضوع البيانات المسجلت للمـراجعت والتنقيح ومراقبت الجودة بواسطت الوحدات والأقسام المختصت بالمركز الوطني للأرصاد الجويت. توفر سجل الرصد بشكل متكامل وخلوه من التقطع وعدم وجود أي فاقد طوال فترة الرصد. الجدول 3 يبين بعض المعلومات الأساسيت عن محطت

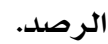

ولزيادة التوضيح تم إضافت جزء آخر من البيانات والمعلومات الخاصت بالتيارات الهوائيت النفاثت (الرياح النفاثت) التي تم رصدها بواسطت محطت طرابلس لأرصاد الأجواء العليا [25]، وذلك للتعرف بوضوح على الاتجاهات السائدة للتيارت النفاثت (Jet Streams) عند المستوى الضغطي 300 هيكتوبسكال (30,000 قدم 9,200 متر فرق مستوى سطح البحر)، تهثلت عينت البيانات التي تم تحليلها يِّ الرصدات اليوميت للأجواء العليا التي قامت المحطت بتسجيلها عند الساعت 12:00 توقيت عالمي خلال الفترة الزمنيت (من بدايت شهر مارس 1987 حتى نهايت شهر فبراير 1989)، وقع الاختيار على هذه العينت من البيانات للأسباب الآتيت : إن عمليت رصد وتسجيل البيانات تم إجراؤها وفق

جدول (3). المعلومات الأساسيت لمحطنتالرصد

\begin{tabular}{|c|c|c|c|c|}
\hline \multirow{2}{*}{ ارتفاع المحطت فوق مستوى البـحر (متر) } & \multicolumn{2}{|c|}{ الإحـداثيـات الجغرافيـت } & \multirow{2}{*}{ الرقم الدولي } & \multirow{2}{*}{ اسهم المحطت } \\
\hline & خط الطول & خط العرض & & \\
\hline 82 & 13:09 شـرقا & 32:40 شمالا & 62010 & طرابلس \\
\hline
\end{tabular}

$$
\text { نهايت شهر أغسطس 1988). }
$$

فصل الخريف لسنت 1988 (من بدايت شهر سبتمبر حتى نهايت شهر نوفمبر 1988).

فصل الشتاء لسنت 1989/88 (من بدايت شهر ديسمبر

$$
88 \text { حتى نهايت شهر فبراير 1989). }
$$

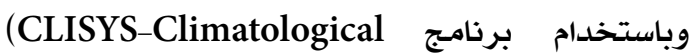

Data Management System) الرياح للفترة السنويت وللفترات الفصليت كلاً على حدة، كما هو مبين بالشكل 13، وبالتالي تم التوصل إلى نتيجت هامتت جدا تمثلت يِّ التعرف على الاتجاهات السائدة للتيارات الهوائيت النفاثت، ويبدو بكل وضوح أن تلك الاتجاهات تتسهم بالثبات والاستقرار خلال كافت فصول السنت وهي تهب من خلال القطاع المحصور بين (200 درجت و 337 درجت)، وبناء على ذلك فإن الاتجاه الأساسي السائد هو الاتجاه الغربي، وهو متماثل تماما مـع الاتجاه السائد الذي قمنا باستخلاصده من خلال الخرائط السينوبتيكيت، أي أن الاتجاه السائد للتيارات النفاثت يِ الأجواء الليبيت غربي بشكل عام، وهو محصور بين الاتجاهين الشمالي الغربي والجنوبي الغربي وهذه الخاصيت
تم القيام بتحليل هذه البيانات عبر تنفيذ سلسلت من الخطوات لمعالجت البيانات اليوميت لسرعت واتجاه التيارات الهوائيت النفاثت (الرياح النفاثت) وتحويلها إلى صورة بيانات سنويت وفصليتحيث تم تصنيفها وترتيبها وفق النسق الآتي: الفترة السنويت (من بدايت شهر مارس 1987 حتى

$$
\text { نهايت شهر فبراير 1989). }
$$

فصل الربيع لسنت 1987 (من بدايتّ شهر مارس حتى

$$
\text { نهايت شهر مايو 1987). }
$$

فصل الصيف لسنت 1987 (من بدايت شهر يونيو حتى نهايت شهر أغسطس 1987). فصل الخريف لسنت 1987 (من بدايت شهر سبتمبر حتى نهايت شهر نوفمبر 1987). فصل الشتاء لسنت 1988/87 (من بدايت شهر ديسمبر 87 حتى نهايت شهر فبراير 1988). فصل الربيع لسنت 1988 (من بدايت شهر مارس حتى نهايت شهر مايو 1988). فصل الصيف لسنت 1988 (من بدايت شهر يونيوحتى 
التيارات الهوائيت النفاثت خلال الفترة من بدايت شهر مارس 1987 حتى نهايت شهر فبراير 1989.
تعتبر هامت ومشجعت جدا ِِِ حال استخدام التوربينات الريحيت المعلقت. الجدول 4 يبين النسب المئويت لتكرار اتجاه

جدول (4). التكرار الفصلي والسنوي لاتجاهات التيارات الهوائيت النفاثت عند ارتفاع 9200 متر فوق مستوى سطح البحر

خلال الفترة (من بدايتتشهر مارس 1987 حتى نهايت شهر فبراير 1989).

\begin{tabular}{|c|c|c|c|c|c|c|c|c|c|}
\hline \multicolumn{9}{|c|}{ النسبت المئويت لتكرار اتجاه التيارات الهوائيت النفاثت خلال فترات الرصد } & \multirow{2}{*}{ التجاه تدفق التيارات } \\
\hline الفترة الكليت & شتاء & خريف & صيف & ربيع 1988 & شتاء & خريف & صيف & ربيع 1987 & \\
\hline 1.5 & - & - & - & 4.2 & 2.9 & - & - & 4.7 & $337.5-022.5$ \\
\hline 0.4 & 3.3 & - & - & - & - & - & - & - & $022.5-045.0$ \\
\hline 1.6 & 6.7 & - & - & - & 5.9 & - & - & - & 045.0-077.5 \\
\hline 1.8 & 3.3 & - & - & 8.3 & 2.9 & - & - & - & $202.5-225.0$ \\
\hline 18.2 & 26.7 & 23.6 & 16.6 & 4.2 & 14.7 & 16.7 & 33.3 & 9.5 & $225.0-247.5$ \\
\hline 25.8 & 30.0 & 17.6 & 16.7 & 29.2 & 29.5 & 33.3 & 33.4 & 16.7 & $247.5-270.0$ \\
\hline 35.0 & 26.7 & 35.3 & 50.0 & 37.5 & 23.6 & 33.3 & 33.3 & 40.5 & $270.0-292.5$ \\
\hline 10.7 & 3.3 & 23.5 & 16.7 & 8.3 & 17.6 & - & - & 16.7 & 292.5-315.0 \\
\hline 5.0 & - & - & - & 8.3 & 2.9 & 16.7 & - & 11.9 & $315.0-337.5$ \\
\hline$\% 100$ & 100 & 100 & 100 & 100 & 100 & 100 & 100 & 100 & المجموع (\%) \\
\hline
\end{tabular}

ويزداد هذا المتوسط تدريجيا بازدياد الارتفاع حتى يصل أعلى

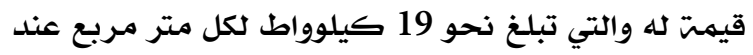
ارتفاع 12,000 متر وذلك داخل النطاق الجوي المحيط بدائرة

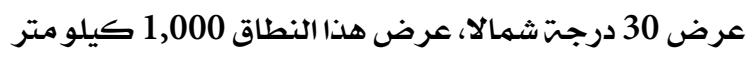

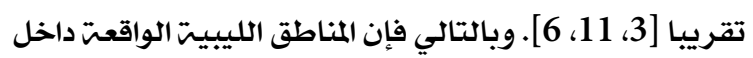
هذا النطاق تعتبر مناطق مرشحت كمجال لإن حقلي مؤهل

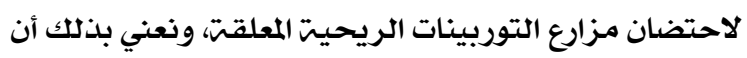
مصدر طاقت التيارات الهوائيت النفاثت متوفر ومتاح.

\section{9. هل بإمكان ليبيا الاستفادة من طاقة التيارات

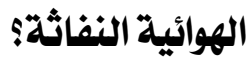

إن ما تستهلكه البشريت من الوقود الأحفوري ٌِِ عام واحد

هو نتاج أمضت الطبيعت ِِّ صنعه مليون عام تقريبا [27]،

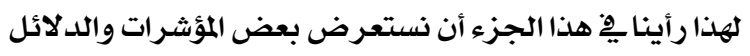
التي تبين إمكانيت استفادة ليبيا من طاقتة التيارات الهوائيت
تجدر الملاحظت أن الجدول 4 يحتوي على القطاعات أو الشعاعات الدالتّ على الاتجاهات الحقيقيت لحركت الجدات الرياح النفاثت خلال فترة الدراست، ولتبسيط الجدول والاختصار هِّْ مساحته فقد تم حذف القطاعات الأخرى التي لهم تكن

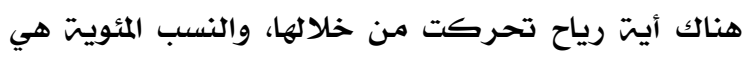

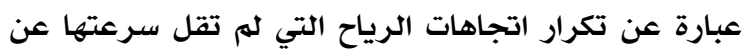
60 عقدة كحد أدنى وهي السرعت التي عندما تبلغها الرياح

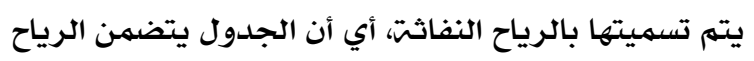

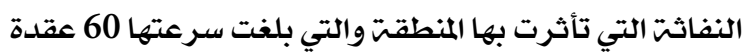
أو أعلى من ذلك. يقدر متوسط كثافت القدرة الذي يمكن توفيره بواسطت التوربينات الريحيت المعلقت على مناطق شمال ووسط ليبيا بنحو 4 كيلوواط لكل متر مربع على ارتفاع يبدأ من 15000 قدم (4600 متر) فوق مستوى سطح البحر، 


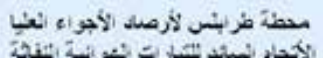

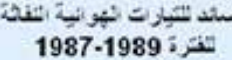

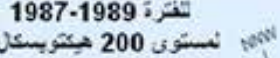
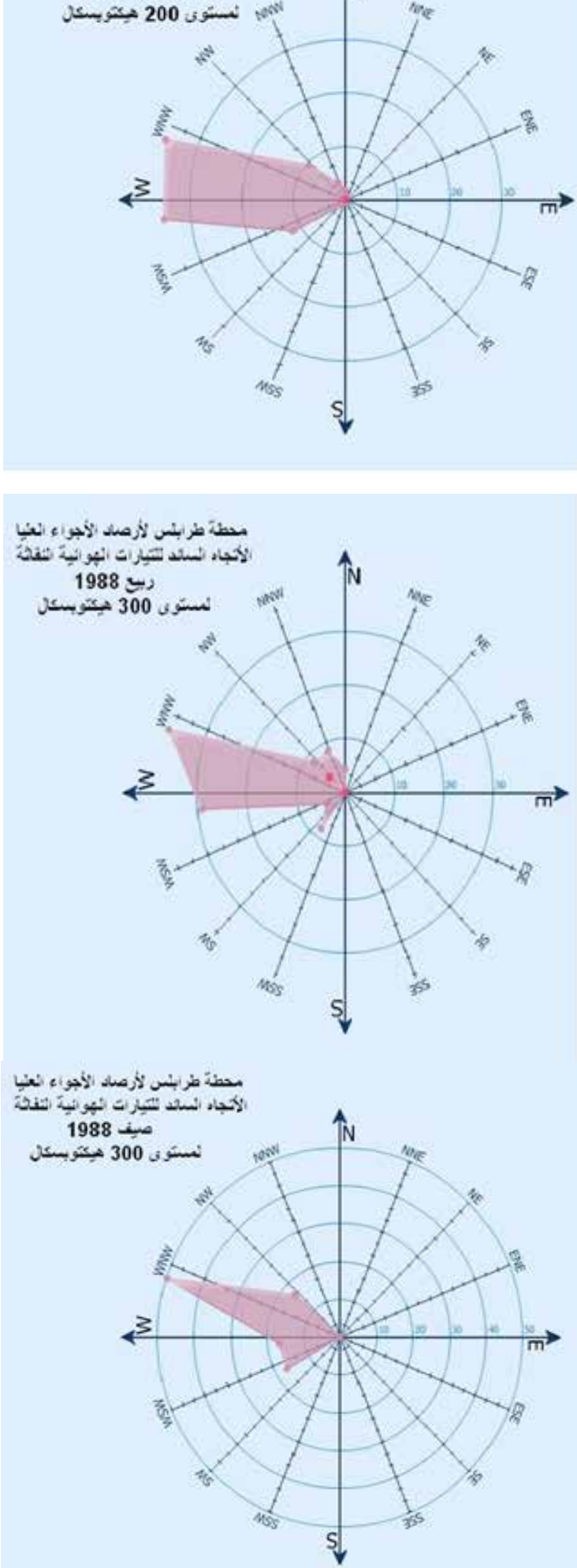

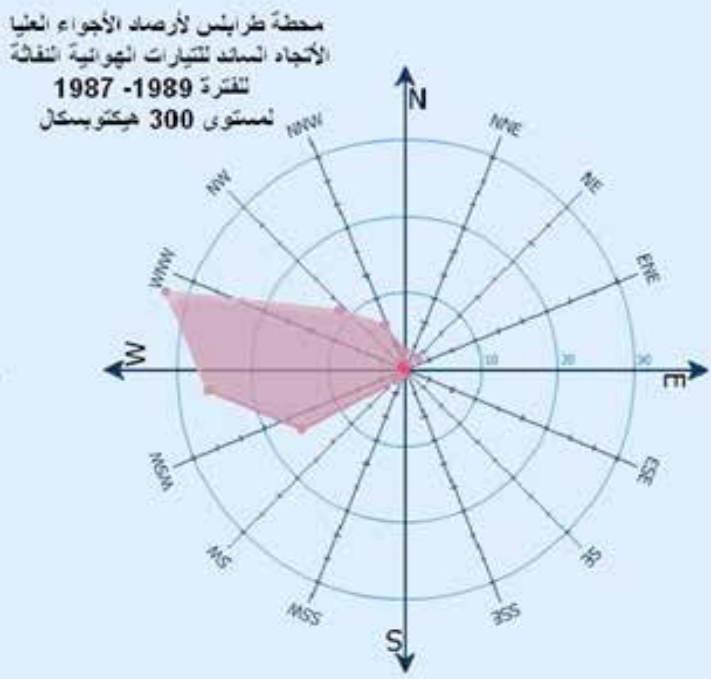

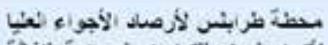

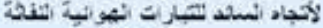
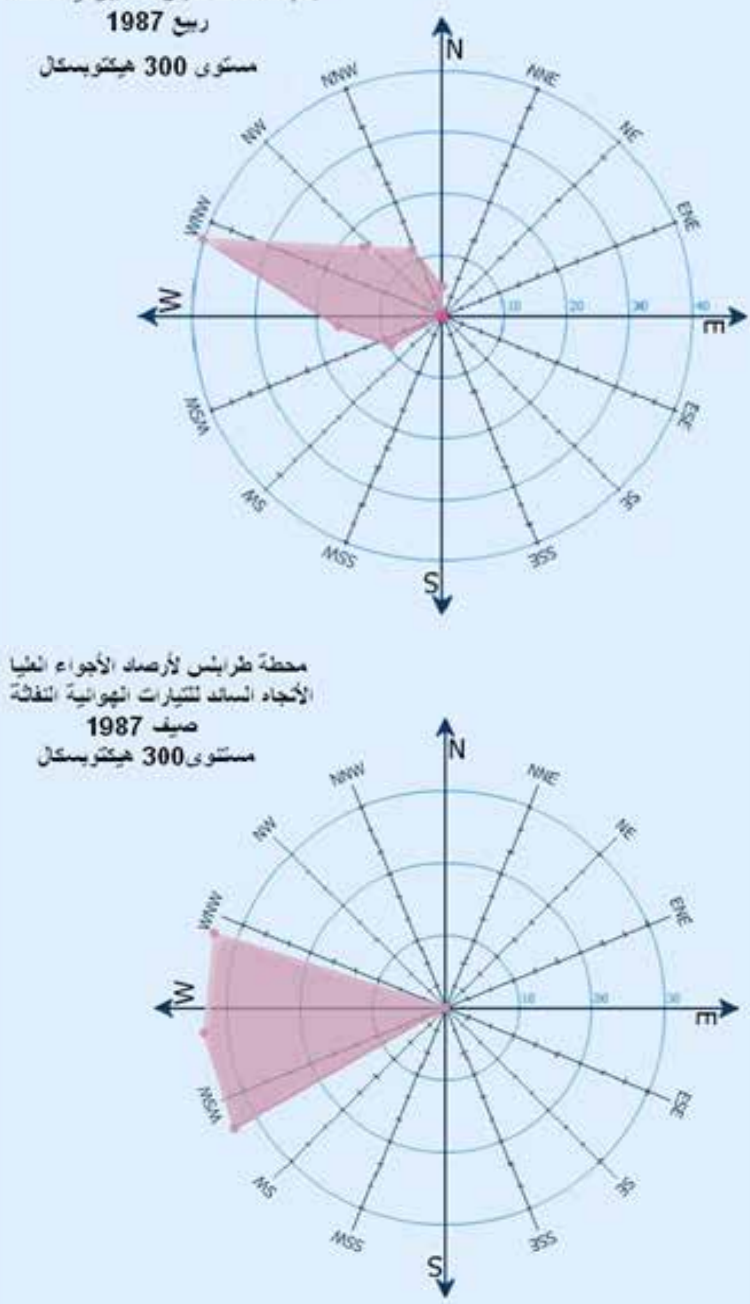


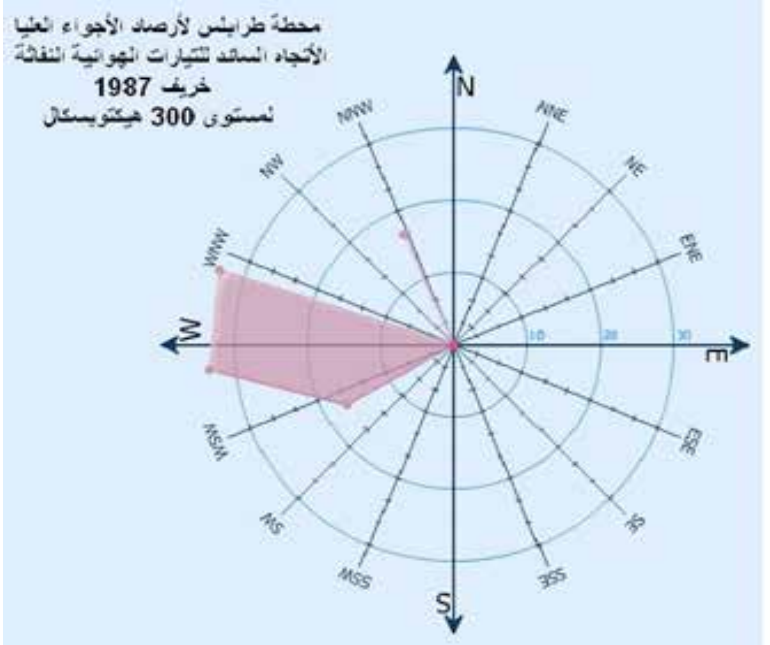

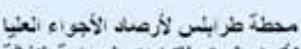

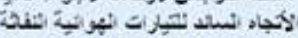

$1988+$

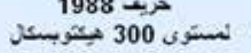
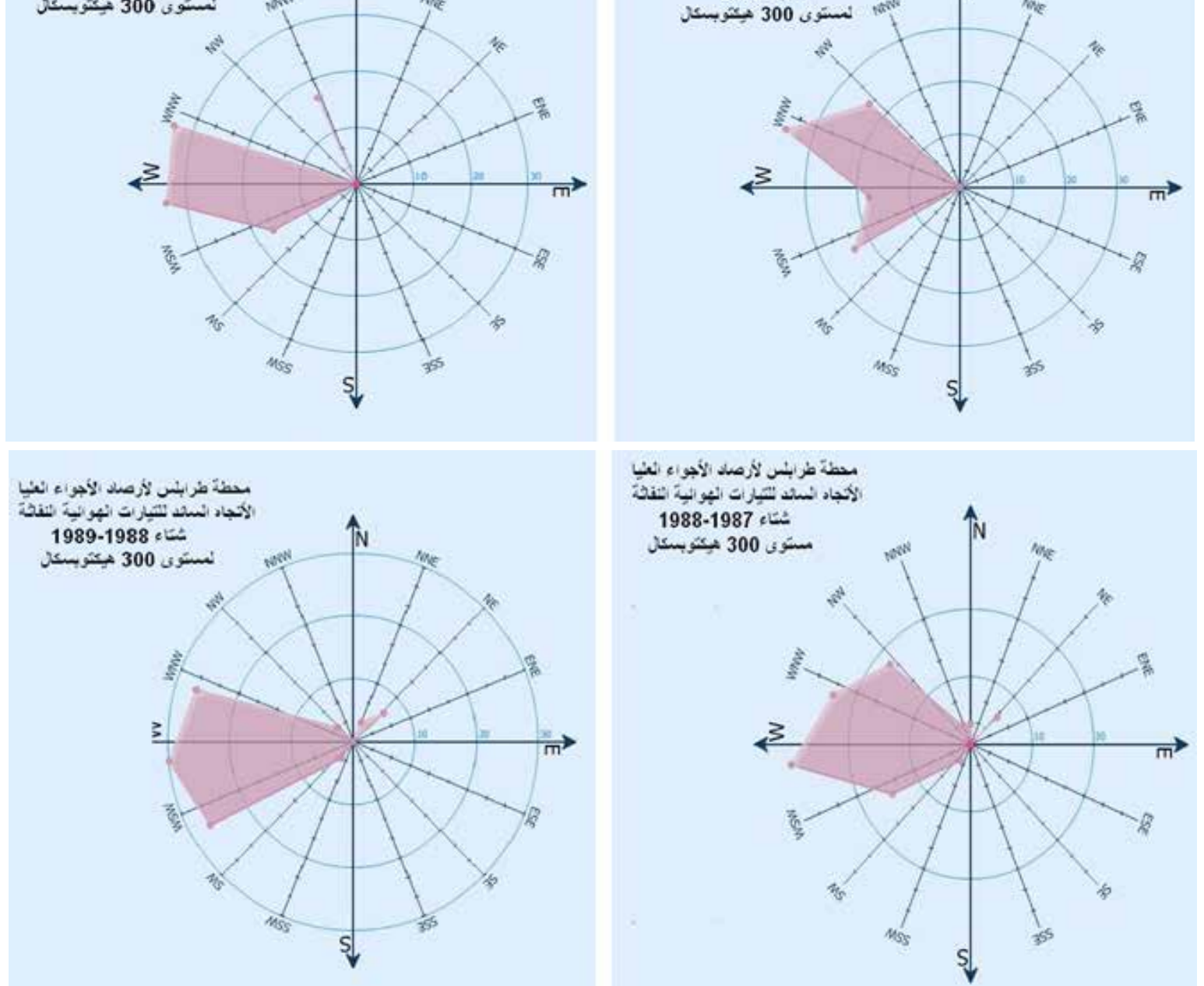

الشكل (13). اتجاهات التيارات الهوائيتت النفاثت السنويتت والفصليتت عند ارتفاع 9200 متر فوق مستوى سطح البحر

خلال الفترة (من بدايتششهر مارس 1987 حتى نهايتشهر فبراير 1989)، محطتّطرابلس لأرصاد الأجواء العليا.

على الرغم من تزحزح نطاقها شمالا وجنوبا مـع

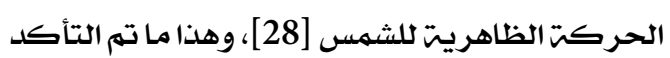
منه بواسطت هذه الورقت وذلك من خلال تحديد الاتجاه السنوي والاتجاهات الفصليت للرياح النفاثت التي تم الحصول عليها بعد تجميع ومعالجت وتحليل البيانات اليوميت التي سجلتها محطت طرابلس لأرصاد الأجواء العليا والمتمثلتة ِِِ سرعت واتجاه التيارات الهوائيت النفاثت.

تتزحزح مواقع التيارات الهوائيت النفاثت شبه المداريت نحو الجنوب ِِّ الشتاء ونحو الثمال يِّ فصل الصيف، كما ان التيارات النفاثت شبه المداريت أقوى ِِِ الشتاء
وقوع السماء الليبيت تحت تأثيراتها ِِِ أغلب الأوقات، حيث إن أهم المناطق التي توجد فيها التيارات النفاثت هي المنطقت الواقعت بين درجتي عرض 28 - 35 درجت

شمالا.

تمتاز الرياح ِِِ طبقات الجو العليا بالرتابت وثبات الاتجاه بشكل عام أي أن لهذه التيارات الهوائيت النفاثت مسالك واتجاهات تكاد تكون شبه ثابتت، وهي تحدث بصورة مستهرة طوال أيام السنت، فقد أوضح الأستاذ تريوارثا بأنه لا يوجد أي تغير فصلي ِِ مسالك أو

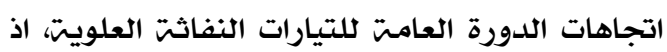
تبين أن نظام مسالكها يكاد يكون ثابتا طول أيام السنت 
الطاقات المتجددة حيث إنه ِِّ الصيف بالإمكان الاستفادة من الطاقت الشمسيتة وعندما يحل الثتاء وتغشى السحب سهماء المنطقت يكون هناتك بديل جيد عن طريق الاستفادة من طاقت التيارات النفاثت.
منها يخ الصيف ولعل ذلك يرتبط بمدى الفرق ه درجت الحرارة بين المناطق المداريت والقطبيتة والذي يزيد عنه يِّ الصيف، وتعمل هذه الخاصيت على منح مناطق شمال ووسط ليبيا فرصت جيدة للاستثمار يو

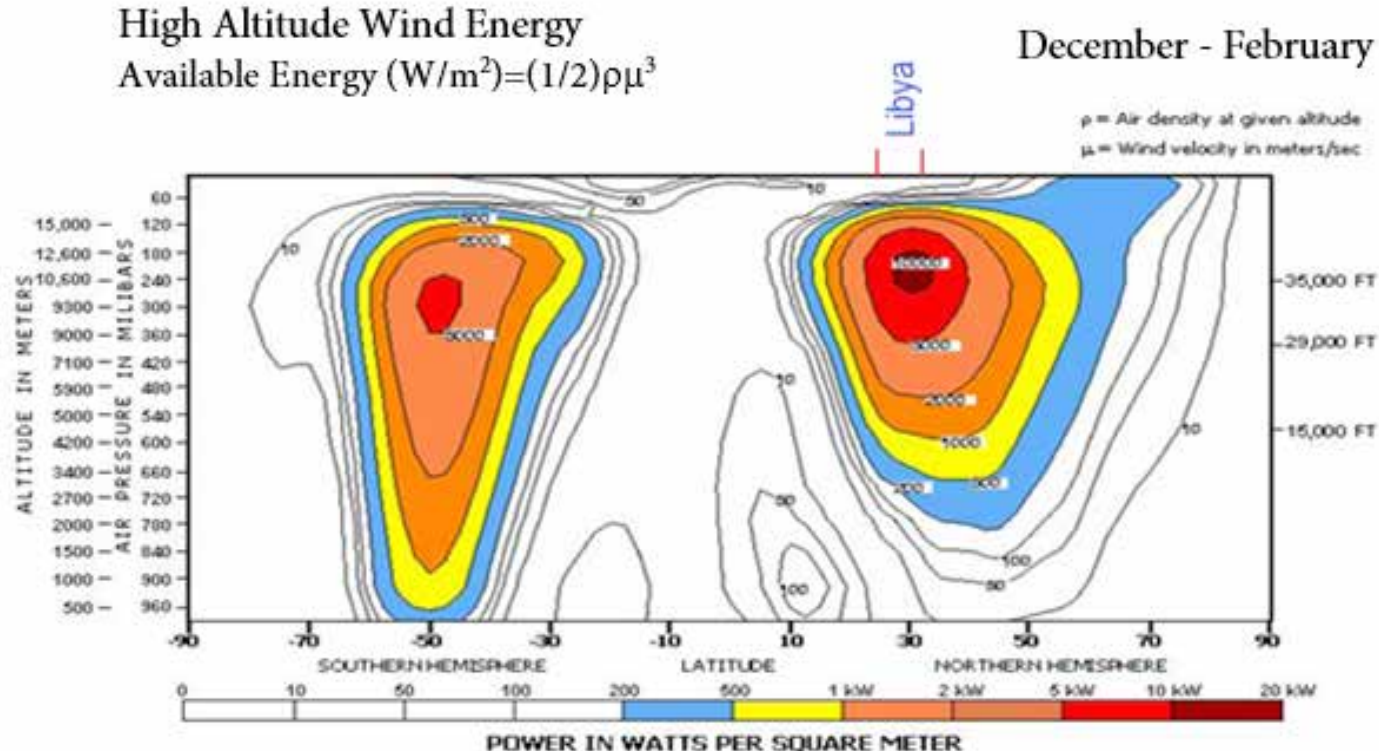

POWER IN WAITS PER SOUARE MEIER

الشكل (14). كثافتّالطاقت كـدالتّ في الارتقاع ودوائر خطوط العرض [26].

ويساهم ٍِِ بناء الاحتياط النقدي ايضا، وتكتسب أسعاره المجزيت الدور المتميز يِ الاقتصاد الوطني، وبه تزداد فرص نمو هذا الاقتصاد لتحسين معيشت المجتمـ، إلا أن النفط يعتبر ثروة ناضبتة، وبالنظر للحاجت الماستة إلى بذل المساعي والمبادرات الجادة لتحويل الوعي بهذه الحقيقت إلى خطط وسياسات وأعمال وبحوث علميتي ـِ ميدان البدائل الاقتصاديت اعتمادا على الطاقات المتجددة، فإننا نوصي بالعمل على تنفيذ مشروع وطني تجريبي (R and D National Proto-Type Project) فترة زمنيت تمتد لخمس سنوات، يهدف هذا المشروع بشكل مـحدد إلى تطبيق تقنيات التوربينات الريحيت المعلقت لغرض توليد الطاقت الكهربيت من التيارات الهوائيت النفاثت المتوفرة بالأجواء الليبيت، وتتألف البنيت المقترحت لهذا المشروع من

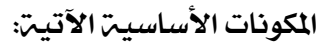

عدد أربع توربينات ريحيت معلقتة (مولدات كهربيت

$$
\text { محمولت جوا). }
$$

أسلاك ألومنيوم موصلت للكهرباء تستخدم لربط التوربينات وٌِِ نفس الوقت تستخلم لنقل الطاقت
تزداد سرعت الرياح بالارتفاع وذلك بسبب تناقص معامل خشونت سطح الأرض، وتستمر ٍِِ الزيادة حتى ارتفاع أربعت كيلومترات تقريبا حيث يتلاثى نهائيا أي تأثير لعامل الاحتكالك، ولهذا يمكن اعتبار مستوى أربعت إلى خمست كيلومترات كارتفاع مناسب للتوربينات الريحيت المعلقت، أي أن الجزء السفلي من التيار النفاث يبدأ عند هذا المستوى وهو المستوى الذي تتوفر به السرعت الآمنت للتوربينه، حيث إن بؤرة التيار النفاث التي توجل عند ارتفاع 12 كم تعتبر منطقت يجب تفاديها من أجل سلامت المعدات التي قد تتعرض للتلف بسبب السرعت الشديدة للرياح. نظرا لاتسـاع رقعت مساحت ليبيا الجغرافيت فإن ذلك يزيد من توفر فرصت الحصول على الحقول المناسبت

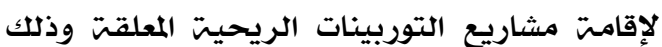
باختيار مواقع مناسبت بضواحي المدن والقرى الشماليت والوسطى. 10ـ التوصبيــــــات

يغذي مورد النفط ميزانيت ليبيا بقسط كبير جدا 


$$
\text { المحلي والدولي. }
$$

استنباط توصيات خاصت موجهت لاتخاذ قرار بشأن تحديد مدى التوسع ِِ استخدام واقتناء التقنيت للانتقال من طور التجريب إلى طور الاستثمار.

\section{1ـ النتائج المتوقعة للمشروع}

ِِِ حالت نجاح المثروع والتمكن من تنفيذه بطريقت مثلى في

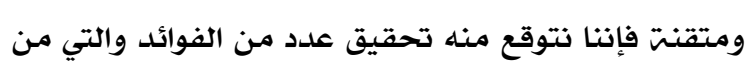

$$
\text { بينها الآتي: }
$$

تخفيف الحمل عن الشبكت الوطنيت للكهرباء وتخفيف

الضرر اللاحق بالبيئت من جراء استخدام محطات توليد الطاقت الكهربيت التي تعمل بالوقود الأحفوري. تخفيض معدلات استهلاك الطاقت التقليديت والمحافظت عليها كاحتياطي استراتيجي للأجيال

$$
\text { القادمهت. }
$$

$$
\text { توفير آلاف الوظائف الجديدة والمتنوعت. }
$$

رفد الاقتصاد الوطني ومساعدته على الخروج من

$$
\text { الركود إلى عصر جديد من النمو. }
$$

المساهمت يِ تنميت الأماكن النائيت ورفع المستوى

تبؤ المنزلت المستقبليت المرموقت ِِِ السوق العالميت للطاقت المتجددة.

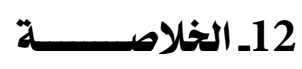

تعتبر التيارات الهوائيت النفاثت بهثابت خزان ضخم للطاقت، وهي متوفرة ومتاحت بالأجواء الليبيت، ويقدر متوسط كثافت القدرة الذي يمكن توفيره منها بهناطق

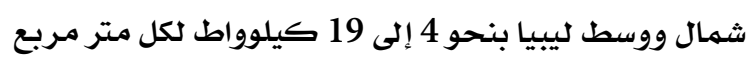
ويتوقف ذلك على الارتفاع الذي يتراوح بين 4,000 إلى 12,000 متر فوق مستوى سطح البحر، وبالتالي يجب النظر إليها كمورد طبيعي استثماري يمكن أن يحقق مكاسب هامت لأجيال المستقبل، كما يجب النظر إلى تقنيات التوربينات الريحيت المعلقت نظرة جادة واعتبارها أداة حقيقيت بالإمكان الاعتماد عليها لإنزال الطاقت من السماء إلى الأرض، ويهكن تحقيق ذلك بواسطت الدعم الجاد لمؤسسات البحث العلمي
الكهربيت من التوربينات إلى المحطت الأرضيت ومن ثم

$$
\text { إلى شبكت التوزيع. }
$$

ه محولات لتوصيل المولدات الكهربيت المحمولت جوا

$$
\text { بشبكت الكهرباء الأرضيت. }
$$

أكشاك للمراقبت والصيانت، وملحقات التشغيل والتجهيز. حقل تجريبي دائري يبلغ قطره نحو 10 كيلومترات لتوفير حيز كافٍ لإبقاء الأجهزة متباعدة عن بعضها مسافت كيلومتر وهو هامش هبوط آمن هِِ حالت

$$
\text { الطواريء. }
$$

نظام خاص لحفظ وأرشفت البيانات والمعلومات

$$
\text { الخاصتَ بالمشروع. }
$$

فريق عمل تنفيذي يضمى عددًا من الخبراء والمهندسين

$$
\text { والفنيين. }
$$

$$
\text { هيئتة إثـرافيت. }
$$

يطمح هذا المشروع إلى تحقيق رزمته من الأهداف المحلددة

$$
\text { تتلخص سِِ الآتي: }
$$

تسجيل الرصدات المعلوماتيت طوال فترة التجربت

$$
\text { بخطوة زمنيت قدرها سـاعت واحدة. }
$$

$$
\text { تجميع ومعالجت وتحليل البيانات المرصودة. }
$$

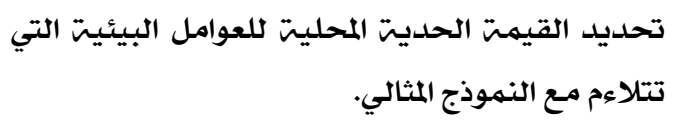


سله الأولويات بهدف استكشاف وتثخيص مدىى إمكانيت الاستفادة الليبيت الذاتيت من طاقت التيارات الهوائيت النفاثت الكامنتّ بطبقات الجو العليا. ولتبسيط الدخول يِّ هذا المجال نقترح العمل على تصميم وتنفيذ مشروع تجريبي وطني يكون هدفه الأساسي البحث والتطوير تمهيدا للدخول يِ تجربت استثماريت واعدة خلال المستقبل.
والتطوير التقني من أجل تأمين الخبرات العلميت والتقنيت الفعالتّ وتحفيزها للقيام بلدور التطوير والابتكار. لذا نأمل من فئات الباحثين والمتخصصين ومخططي ومنفذي السياسات الاقتصاديت والبيئيت والتتهويت بالمؤسسات الوطنيت وصناع القرار الذين يهتمون بمجالات الطاقت المتجددة دراست هذا الموضوع بشكل أشمل من كافت جوانبه وإدراجه ضمن جدول (5). برنامج خطت العمل المقترحتّللمشروع

\begin{tabular}{|c|c|c|c|c|}
\hline إجراءات إداريت وفنيت & & النشاطات المستهدفت & الفترة الزمنيت & المرحلة \\
\hline 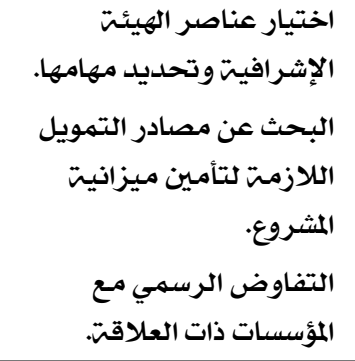 & - & 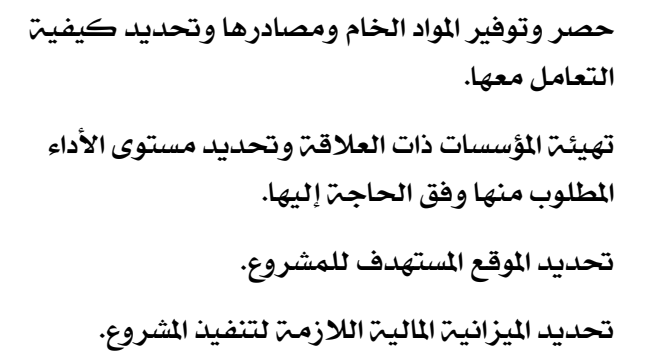 & 6 أشهر & 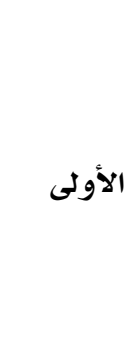 \\
\hline التنفيذيار عناصر الفريق الفني & - & 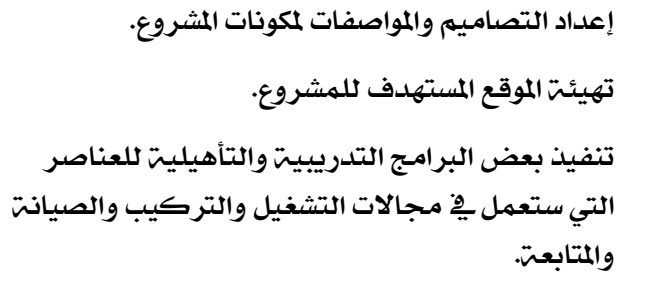 & 6 أشهر & 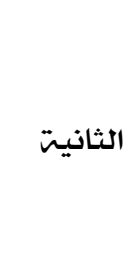 \\
\hline متابعت التنفيذ إدارياً وفنياً. & - & الشروع ِِّ بناء وتركيب مكونات المشروع. & 6 أشهر & الثالثة \\
\hline ملتى تسيعت العناصر القـائمست & - & حفظ التشغيل التجريبي للمشروع. & 36 شهرًا & الرابعت \\
\hline 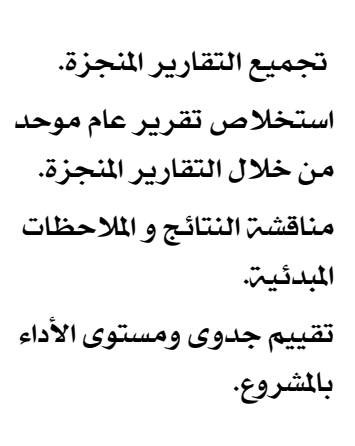 & - & 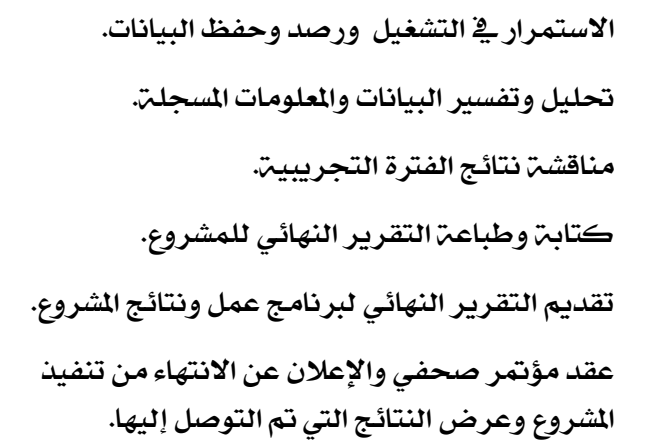 & 6 أشهر & الخامستة \\
\hline
\end{tabular}

[2]- http: en.wikipedia.org/wiki/talk:Airborne-

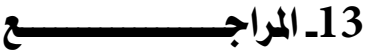
wind-turbine.

[3]-J. D. Atkinson et al. (1979): The use of
[1]-Al Bayan. Ae (2001): Airborne Wind Turbine, Al Bayan Newspaper. 
Transactions on Energy Conversion, vol. 22, No. 1.pp. 1-10.

[12]-Bryan W. Roberts and D. H. Shepards (2003): Unmanned Rotorcraft to Generate Electricity Using Upper Atmospheric Winds, Proceedings of the Tenth Australian International Aerospace Congress, Engineers Australian Brisbane, Australia, Paper AIAC 2003-098.

[13]-GWEC (2006): Global Energy Outlook 2006, Global Wind Energy Council. p. 9.

[14]-GWEC (2006): Global Wind Energy 2006 Report, Global Wind Energy. Council. p 8

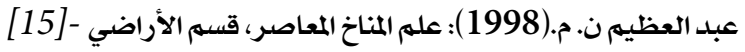
والمياه، كليت الزراعت، جامعت الإسكندريت ص 265-272

[16]-Lorenz E. N. (1967): The nature and theory of the general circulation of the atmosphere. pp. 59-78

السامرائي ق. م. (2005): المناخ والأقاليم المناخيت. دار -[17] اليازوري العلميت للنشر والتوزيع ص 106 - 115

[18]-Krishnamurti, T. N. (1961): The Subtropical Jet Stream of winter, Journal of Meteorology, Volume 18, pp. 172-190.

[19]-Newton, C. W. and Persson, A. V. (1962): Structural characteristics of the subtropical jet stream and certain lower - Stratospheric wind system, Tellus XIV,2 pp. 222-240.

[20]-Lamb. H, and others (1957): Jet Streams over North Africa and the Central Mediterranean in January and February, 1954, The Meteorological Magazine, vol. 86, No1,018 pp. 97-111.

[21]-Bargman D. J. (1960): Tropical Meteorology in Africa, Munitalp Foundation Nairobi, pp. 86-96.

[22]-Cole F. W. (1980): Introduction to
Australian upper wind data in the design of an electrical generating platform," Chas. Kolling Res. Lab., Unv. of Sydney, Sydney, Australia, TN D-17, pp. 1-19.

[4]-R. J. O'Doherty and B. W. Roberts (1982): Application of upper wind data in one design of tethered wind energy system, Solar Energy Res. Inst., Golden, CO, Tech. Rep. TR-2111400, pp. 1-127.

[5]-Rezaey, A. and D. Safari-Doust, (2012): Feasibility Study of $10 \mathrm{GW}$ High Altitude wind Energy generation station in New York State; Journal of Basic and Applied Scientific Research. Semnan University, Iran. PP. 6119 6126.

[6]- Fagians, L. and Lanesc (2012): Airborne wind energy: an overview, 2012 American Control Conference, Fairmount Queen Elizabeth, Montréal Canada.pp. 3132-3142.

[7]-Fletcher, C. A. J. and B. W. Roberts, (1979): Electricity Generation from Jet-Stream Winds, Journal of Energy, Vol. 3. pp. 241-249.

[8]-Bryan W. Roberts and J. Blackller (1980): Various systems for generation of electricity using upper atmospheric winds, in Proceeding of the 2nd Wind Energy Innov. Syst. Conf, Solar Energy Res. Inst., Colorado Springs, CO, pp. 67-80.

[9]-Bryan W. Roberts (2012): Cost and Security of Electricity Generated by High Altitude Winds. Associate Paper, Future Directions International, Independent Strategic Analysis of Australia's Global Interests, pp. 136-144.

[10]-http://www.Skywindpower.com/ww/index.

[11]-Bryan W. Roberts, and others (2007): Harnessing High-Altitude Wind Power, IEEE 
口-

[26]-Ken Caldeira: High Altitude Wind

Energy, based on ECMWF 1978-1994

Seasonal mean wind and temperature,

(Lawrence Livermore National

Laboratory).

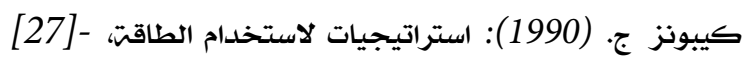

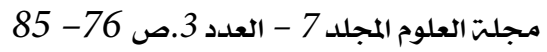

[28]-Trewartha G. T. (1954): An Introduction to Climate.p. 90.
Meteorology, $3^{\text {rd }}$ Edition, pp. 238-243.

[23]-Karamitsu, M. and Others (2002):

NCEPDOE AMIP-II Reanalysis (R-2)

Bulletin of American Meteorological Society 83, pp. 1631-1643.

[24]-Archer, C. L. and K. Caldeira, (2009): Global Assessment of High - Altitude wind power, Energies, Vol. 2.pp. 307-309.

قاعـدة بيـانات المـركز الوطني للأرصاد الجــويت، -[25] طرابلس - ليبيا 